\title{
Human Enhancements and Voting: Towards a Declaration of Rights and Responsibilities of Beings
}

\author{
S. J. Blodgett-Ford ${ }^{1,2}$
}

check for updates

Citation: Blodgett-Ford, S.J. Human Enhancements and Voting: Towards a Declaration of Rights and Responsibilities of Beings. Philosophies 2021, 6, 5. https://doi.org/10.3390/ philosophies6010005

Received: 12 November 2020 Accepted: 23 December 2020 Published: 14 January 2021

Publisher's Note: MDPI stays neutral with regard to jurisdictional clai$\mathrm{ms}$ in published maps and institutional affiliations.

Copyright: (C) 2021 by the author. Licensee MDPI, Basel, Switzerland. This article is an open access article distributed under the terms and conditions of the Creative Commons Attribution (CC BY) license (https:// creativecommons.org/licenses/by/ $4.0 /)$.
1 Boston College Law School, Boston College, Newton Centre, MA 02459, USA; blodgesa@bc.edu GTC Law Group PC \& Affiliates, Westwood, MA 02090, USA

\begin{abstract}
The phenomenon and ethics of "voting" will be explored in the context of human enhancements. "Voting" will be examined for enhanced humans with moderate and extreme enhancements. Existing patterns of discrimination in voting around the globe could continue substantially "as is" for those with moderate enhancements. For extreme enhancements, voting rights could be challenged if the very humanity of the enhanced was in doubt. Humans who were not enhanced could also be disenfranchised if certain enhancements become prevalent. Voting will be examined using a theory of engagement articulated by Professor Sophie Loidolt that emphasizes the importance of legitimization and justification by "facing the appeal of the other" to determine what is "right" from a phenomenological first-person perspective. Seeking inspiration from the Universal Declaration of Human Rights (UDHR) of 1948, voting rights and responsibilities will be re-framed from a foundational working hypothesis that all enhanced and non-enhanced humans should have a right to vote directly. Representative voting will be considered as an admittedly imperfect alternative or additional option. The framework in which voting occurs, as well as the processes, temporal cadence, and role of voting, requires the participation from as diverse a group of humans as possible. Voting rights delivered by fiat to enhanced or non-enhanced humans who were excluded from participation in the design and ratification of the governance structure is not legitimate. Applying and extending Loidolt's framework, we must recognize the urgency that demands the impossible, with openness to that universality in progress (or universality to come) that keeps being constituted from the outside.
\end{abstract}

Keywords: human enhancements; voting; human rights; ethics; discrimination; racism; speciesism; ableism

\section{Introduction}

The phenomenon and ethics of "voting" will be explored in the context of "human enhancements", which, for purposes of this analysis, are broadly defined as intentional modifications of a person who is accepted prior to the enhancement as genetically human, of any possible type of modification or combination of types. ${ }^{1}$ Enhancements may be made with or without the consent of the enhanced human. For example, an enhancement could be made prior to birth (or prior to the age at which consent is recognized as valid) or could be forced on the human. Or an enhancement could be made with consent by, or at the request of, the enhanced human. In most cases, the enhancement is perceived as a way to "improve" the human, such as by improving their physical, mental or emotional abilities, but the analysis herein does not require that the enhancement actually be an improvement under any ranking theory or particular perspective. Enhancements can also be permanent or temporary.

In Section 2, "voting" will be examined for enhanced humans who fall into two broad categories - those with moderate enhancements, where the "humanity" of the enhanced

1 For purposes of this analysis, a descendant of a "human" (Homo sapiens) who was genetically or otherwise altered to such an extreme that they would no longer commonly be perceived to be "human" (or who no longer even had an organic embodiment) is still defined as an "enhanced human". However, in Section 3, we will propose to eliminate the requirement of "humanity" in voting rather than using such a "Grandfather Clause" approach and instead broadly extend voting rights to all living beings and all conscious beings. 
person is not seriously in question, and those with extreme enhancements, where humans who lacked similar enhancements would likely question the "humanity" of the enhanced human. The question of who has the right to vote and how they can vote will be explored primarily in the context of voting in the United States at the federal level. Existing patterns of discrimination around the globe would likely continue substantially "as is" for humans with physical and mental enhancements who are viewed as "still human." For the "beyond human" category of enhancements, the established rules and practice of voting are likely to be directly challenged. For both moderate and extreme enhancements, humans who are not enhanced (or are less enhanced) may be disenfranchised if certain enhancements become prevalent among the voting population.

In Section 3, voting by enhanced and non-enhanced humans will be examined using an extension of a theory of engagement articulated by Professor Sophie Loidolt that emphasizes the importance of legitimization and justification and "facing the appeal of the other" to determine what is "right" "from a phenomenological first-person perspective [1]. Seeking inspiration from the Universal Declaration of Human Rights (UDHR) of 1948 [2], voting rights and responsibilities will be re-framed from a foundational working hypothesis that all conscious and all living "beings" (including enhanced and non-enhanced humans) should have a right to vote directly. Representative voting should be considered as an admittedly imperfect alternative where direct voting is not possible, such as due to communication limitations, or as an additional option to direct voting, in the case of a group that suffers from historic systematic discrimination. Finally, the framework in which voting occurs, as well as the processes, temporal cadence of voting, and role of voting in the overall architecture and functioning of government, should be seen as provisional pending a "to be determined" approach (or approaches) designed, modified, refined, abolished and rebuilt from scratch as needed, with the participation from as diverse a group of beings as possible. Voting in a particular structure of governance has not been legitimized if it is delivered by fiat "as is" to those beings who were excluded from participation in the design and ratification of such structure-whether because they were enhanced to an extreme level or because they were not enhanced/less enhanced. Applying an extension of Loidolt's framework, we must recognize the urgency that demands the impossible with openness to that universality in progress (or universality to come) that keeps being constituted from the outside.

\section{Discussion-Human Enhancements and Voting-Moderate and Extreme}

Common assumptions about who has the right to vote and what "voting" involves warrant careful examination to see what they reveal, what they hide, and what they can tell us about biases that might exist against enhanced humans (or non-enhanced humans) who are perceived as "other" or "lesser" than those who hold political power. For purposes of this analysis, the meaning of "enhanced" shall be any intentional modification of a human being, whether done prior to birth (e.g., through genetic engineering of human embryos), or after birth, such as through implants, chemical enhancements, or other modifications. While such enhancements are often intended to be efforts to "improve" the human being who is enhanced, either with or without the consent of the enhanced person, for purposes of this analysis there will be no effort to assess whether such enhancements are actually an "improvement" or "benefit" to the enhanced human, to their family, to any broader group, or to society generally. One person might view an increase of intelligence as an "improvement" while another might view it as a negative change if the enhancement was only to computational abilities or analytical intelligence without any corresponding increase in capacity for empathy, compassion or "emotional intelligence." Similarly, a person who was born as a female biologically and then underwent surgery to become male might view it as an improvement for themselves as they felt their body reflected their true identity more accurately, but another person might view the loss of child-bearing capacity as a negative. As a final example, someone who values an idealized "normative" "able" human body might view an enhancement to a human body that brings that body closer 
to their ideal norm as an enhancement, while a person who embraces diverse forms of embodiment and living might consider such a modification as a negative. ${ }^{2}$

The present analysis of voting and human enhancements is agnostic as to the benefits of enhancements. We assume that enhancements (for better or for worse) are already occurring and are likely to occur in the future, potentially with greater variations, increasing numbers and extremity, and may be permanent, semi-permanent or reversible at will. In this context, we explore the effects of biases in the history of voting in the United States, using the examples of ancestry and gender, and consider how they might continue for both moderate and extreme human enhancements.

Restrictions on voting in the United States have been used to systematically discriminate against humans viewed as "other" or "lesser", in large part to preserve the established distribution of wealth and power. Similar patterns of discrimination can be seen in many other countries-currently and historically, including, just as a few examples, systematic and intentional disenfranchisement of indigenous peoples in Australia, Canada and Japan [7-9]. There is a risk that such discrimination would continue substantially "as is" for humans with physical and mental enhancements who are viewed as "still human." In addition, humans who are not enhanced or who are less-enhanced may be disenfranchised if certain enhancements become so prevalent that they are the "new normal."

For "beyond human" or "no longer human" types of enhancements, the established phenomenon of voting is likely to be directly challenged by extreme physical and/or mental enhancements, including hybrid organic/inorganic humans and mental enhancements such as a "networked consciousness" or an "extended mind." For example, it has been hypothesized that "consciousness does not originate from a single brain section" and instead "originates globally" [10]. If so, it is possible that there could be an enhanced human in the future whose "consciousness" arose from a network of organic and inorganic elements that were distributed (physically) in various locations, potentially even among different human embodiments. Such enhancements would put serious pressure on the United States model that being human is a necessary condition for voting, ${ }^{3}$ both for elected human representatives as well as on votes for particular laws or amendments. Finally, in the case that either moderate or extreme enhancements, such as those contemplated in the DARPA (United States Defense Advanced Research Agency) program, became common among the voting population, non-enhanced or less-enhanced humans may be viewed as disabled or less-abled humans, and they may (legally and in practice) be denied the right to vote $[12,13]$.

For purposes of this discussion, human enhancements may include any intentional physical and/or mental modifications of a human being, made either before birth, such as through gene editing or embryo selection, or after birth, whether by the human being or by another person, with or without the consent of the enhanced human. The term "cyborg" will also, at times, be used to refer to an enhanced human who has a physical or mental enhancement that includes an inorganic component, such as a prosthetic or

2 See [3] (quoting dancer, artist and poet Neil Marcus "Disability is not a 'brave struggle' or 'courage in the face of adversity', disability is an art. It's an ingenious way to live."). Consider also the esteemed composer Molly Joyce, who has to compose without using her left hand, and "has carved a unique sound as a composer by treating disability differently: not as an impediment but as a wellspring of creative potential [4]." An additional example of an "ideal" body relates to skin color. In many countries, due to a legacy of racism, a lighter skin color is viewed as an "improvement" and may objectively benefit the person having such skin color, including in employment opportunities and advancement. Consider the practice of skin bleaching in Jamaica. In his analysis of the practice, Professor Christopher Charles concluded that "self-hate" was not the primary driver for skin lightening in Jamaica and noted that reasons for skin lightening were more nuanced: "Some Black Jamaicans recognize the color and racial distinctions in society. This should not be viewed as self-contempt. It is borne out by their experience that the Blacker one is, the less status and privilege one has in the society. They recognize the reality of contemporary Jamaica. They do not necessarily accept it [5]." In the United States, caste-based discrimination allegedly is occurring in the technology industry [6] ("The lawsuit notes that the employee is Dalit Indian and that he has a darker complexion than non-Dalit Indians.").

3 Non-human corporations and other legal entities that are "persons" under the law can still have influence one election results even though they cannot vote. See the United States Supreme Court decision in the Citizens United case against the Federal Election Commission [11], in which the Court held that limitations on spending for political campaigns by groups, including corporations and labor unions, violate the Constitutional First Amendment right to free speech. 
wearable enhancement or a neural implant. We will consider moderate enhancements first, then turn to extreme enhancements.

\subsection{Moderate Human Enhancements-“Still Human"}

In this section, we will consider voting by people who have been physically or mentally enhanced through moderate enhancements and are still recognized as "human". Such enhanced humans could have a wide variety of physical and/or mental enhancements, or combinations thereof, which could also in theory be malleable throughout their lifetime. For example, physical enhancements could result in an enhanced human being, or appearing to be, of a different ethnicity or ancestry, gender (or genders) or age. Enhancements could also lead to heightened or modified sensory perceptions, such as being able to touch, taste, smell, see, or hear in a different manner than a non-enhanced human. Enhancements could also allow the human to communicate via wifi and or access the Internet directly, such as via neural implants.

In all such cases, in this category of moderate enhancements, the enhancements cannot be so extreme that the person with the enhancements is perceived in their society as being no longer human or inhuman. What would "voting" mean for such enhanced humans? The answer is not clear, and could depend on whether the enhancements were made prior to birth or after birth and whether they were such that the person was characterized as "lesser" or "other" than those humans who were entitled to vote-or who were more able to vote due to enhancements.

The right to representation in government (and the lack of such representation in the English Parliament) was one of the core reasons the American colonists revolted against England. Taxation without representation was viewed as tyranny. ${ }^{4}$ Based solely on this aspect of United States history, it would be easy to conclude that any person who was required to pay taxes to the United States federal government, enhanced or not, would be entitled to vote in United States elections. This simple rule could mean that a human who was physically enhanced and "still human" would have the right to vote if they paid taxes in the United States, regardless of whether they were citizens of the United States or even physically located in the United States.

However, the historical and current phenomenon of voting in the United States greatly deviates from such a simplistic model. Instead, it reflects systematic efforts over hundreds of years-and continuing to the present- to deny the right to vote to those viewed as "other" or "lesser" than the group(s) controlling the wealth and power of the United States-initially wealthy white men from England and later wealthy white women as well $1^{5}[15]$.

\subsubsection{Physical Enhancements-“Ancestry"}

"A free negro of the African race, whose ancestors were brought to this country and sold as slaves, is not a "citizen" within the meaning of the Constitution of the United States" [16]

Based on the legacy of the denial of the right to vote to people of different ancestries or ethnicities in the United States, both as a matter of law and a matter of practice, it seems likely that if a physical enhancement changed a human to actually be (or appear to be) of an ancestry that was not legally entitled to vote (for example, not legally entitled to citizenship under then-current United States laws), ${ }^{6}$ then such a person might not be, in practice, fully enfranchised, particularly if the change was made genetically such that the

4 "Taxation without representation is tyranny" is commonly attributed to attorney James Otis, who was one of the representatives from Massachusetts in the Stamp Act Congress (approx. 1761).

5 In 2018, the richest member of Congress had a Net Worth estimated at $\$ 500,000,000$, and the median net worth of all members of Congress was approximately $\$ 500,000$ [14].

6 Former Professor Rachel Dolezal, who pretended to be Black for decades and was president of the Spokane, Washington chapter of the National Association for the Advancement of Colored People, is just one example of people who have attempted to "pass" as having a different ancestry or ethnicity (although at a time in U.S. history when Blacks were enfranchised, so she did not give up her right to vote in doing so) [17]. 
birth ancestry was modified under the then-applicable laws. Similarly, one might expect that some parents might want to change their child's ancestry to be (or appear to be) that of a more privileged group. In such cases, a human who might otherwise not have the right to vote could, in theory, then have the right to vote, particularly if the change was made prior to birth. All of this analysis of course must be caveated by skepticism toward any scientific definition of "ancestry" and instead relies on the meaning of "ancestry" in the context of citizenship, including for immigrants who seek entry into the United States or naturalization after entry ${ }^{7}[18]$.

American colonists felt they had the rights of English citizens to vote for representatives in Parliament in England. They viewed themselves as retaining their citizenship rights as emigrates and descendants of emigrates from England. However, the right to vote was (and still is) only available for "citizens of the United States." This means that only "native born" United States citizens (but for many years not indigenous peoples) or "naturalized" citizens have the right to vote.

Until the 14th Amendment was ratified in 1868 after the American Civil War, the Supreme Court decision in Scott v. Sanford, 60 U.S. 393 (1857) (the "Dred Scott decision") was the law of the land. Under the Dred Scott decision, even freed slaves who were born in the United States could not become United States citizens (and therefore have a constitutional right to vote) because they were descendants of non-citizens (Africans) [16]. Section 1 of the Fourteenth Amendment granted citizenship to "All persons born or naturalized in the United States." In the infamous decision, the Supreme Court explained that freed slaves "are not ["people of the United States"], and that they are not included, and were not intended to be included, under the word 'citizens' in the Constitution, and can, therefore, claim none of the rights and privileges which that instrument provides for and secures to citizens of the United States. On the contrary, they were at that time considered as a subordinate and inferior class of beings, who had been subjugated by the dominant race, and whether emancipated or not, yet remained subject to their authority, and had no rights or privileges but such as those who held the power and the government might choose to grant them." [16]

Shortly after the ratification of the Fourteenth Amendment, the Fifteenth Amendment was enacted and specified that voting rights could not be "denied or abridged by the United States or by any state on account of race, color, or previous condition of servitude." Having this in the Constitution was of course an important step forward, but as a matter of law and practice systemic racism and white supremacy continued through a process of legal "informal disenfranchisement", in which "a group that has been formally bestowed with a right is stripped of that very right by techniques that the [United States Supreme] Court has held to be consistent with the Constitution." [19]. As Professor Khiara Bridges explains, "While the Fifteenth Amendment formally enfranchised black men, white supremacists in the South employed methods-poll taxes, literacy tests, residency requirements, and white primaries - that made it nearly impossible for black men (and after the passage of the Nineteenth Amendment, black women) to actually vote in the South for a century after their formal enfranchisement. Moreover, the Court held that these techniques of racial exclusion from the polls were constitutional." 8 The equivalent of a "poll tax" as a means to prevent poor people from immigrating to the United States, continues through the fees for applications for naturalization. In a lawsuit, Project Citizenship alleged that an increase in the filing fee for $\mathrm{N}-400$ naturalization applications from the US $\$ 640$ to $\$ 1170$ and a new rule that would allegedly disqualify $97.2 \%$ of green card holders from receiving fee waivers, "constitutes a wealth test for citizenship" [20,21].

7 Ref. [18] ("for most of its history U.S. law treated newcomers differently according to race. Between 1790 and 1952, legislators restricted naturalization-the process by which immigrants become citizens-to particular racial and ethnic groups, with a consistent preference for whites from northwestern Europe. Laws restricted black immigration beginning in 1803, and a series of subsequent measures banned most Asians and limited access by immigrants from southern and eastern Europe.").

8 Ref. [19] at 48-49. 
The Fourteenth and Fifteenth Amendments did not give the right to vote to Native peoples. Indeed, many Native people were legally wards of the government with no political voice [22]. This treatment of indigenous peoples as "non-citizens" even in the land in which they were born echoes the Nuremberg laws of Nazi Germany, which legally classified people defined as "racially" Jewish by law as "subjects" of the state versus people of "German or kindred blood" who could be citizens [23]. The Nuremberg laws later were expanded to cover Black people and the Roma, who were also targets of the Nazi genocide.

Similarly, in the United States, "ancestry" has been used as a proxy for the social construct of "race" or "ethnicity" [24,25]. We can see similar voter suppression measures in the United States that appear to be based on discrimination due to "ancestry." ${ }^{\prime}$ For example, United States citizens "by birth" are not required to pass any test to demonstrate they understand the significance of voting. However, people born outside the United States who want become citizens are required to pass the "civics" portion of the Naturalization Test. There are questions on the test that a relatively small percentage of Americans could answer correctly, such as, for example, "How many amendments does the Constitution have? ${ }^{10 "}$

These types of restrictions were intentionally designed and enforced to disenfranchise those deemed "lesser" or "other" and privilege those who were already "grandfathered" in as voters. The "phrase 'grandfather clause' originally referred to provisions adopted by some states after the Civil War in an effort to disenfranchise African-American voters by requiring voters to pass literacy tests or meet other significant qualifications, while exempting from such requirements those who were descendants of men who were eligible to vote prior to 1867" [30]. "Providing such protection commonly is known-in the case law and otherwise - as 'grandfathering.' We decline to use that term, however, because we acknowledge that it has racist origins." [30]

The Voting Rights Act of 1965 (VRA) prohibited making the right to vote being dependent on whether a citizen was able to read or write, attained a particular level of education, or passed an interpretation "test." However, the VRA does not prohibit such tests in the immigration or naturalization process toward citizenship. Just like a "whitesonly" primary could legally be used to prevent Blacks from participating in voting, if a person cannot even become a citizen (and therefore have a right to vote) without passing a wealth test or literacy test, then the voter suppression has effectively been shifted to an earlier point in time.

What can we learn from this history when we consider human enhancements? First, we should expect discriminatory treatment, and efforts (legal and otherwise) to deny the right to vote or discourage voting, for anyone who has a physical enhancement of a type that makes them seem "other" or "lesser" than those in power. For example, if a person were to enhance their skin color to make it darker, or to modify their physical appearance to look like they were of a different ancestry, they could be subject to targeted discrimination and denial of the right to vote under then-current laws. Second, as will be explored further in Section 3, if "ancestry" (however the term is defined, whether based on physical appearance, some type of genetic marker(s), or place of birth of the enhanced human or of people to whom they are biologically, socially, culturally, or legally related) can be changed via human enhancement technology, then "ancestry" may be an artificial distinction that should no longer be the basis for denial of enfranchisement. Such modifications to "ancestry" might, perhaps, be made either before birth through genetic

9 For example, in U.S. elections in 2012 and 2014, Rosa Maria Ortega, an Hispanic immigrant who was a permanent resident of the United States and was brought to the country from Mexico as an infant, apparently voted without knowing it was illegal and was sentenced to eight years in prison. She then faced deportation [26]. Mexican lawful immigrants are among those least likely to become U.S. citizens [27]. ("desire is high, but about half cite language, cost barriers").

10 U.S. Citizenship and Immigration Service, “Civics (History and Government) Questions for the Naturalization Test,” (rev. 01/19) [28] (Q7: “How many amendments does the Constitution have? twenty-seven (27)") (Q48: "There are four amendments to the Constitution about who can vote. Describe one of them. Citizens eighteen (18) and older (can vote). You don't have to pay (a poll tax) to vote. Any citizen can vote. (Women and men can vote.) A male citizen of any race (can vote)."). For an example of a post-Civil War literacy test that was designed to be impossible to pass, see the Louisiana Literacy Test. "The literacy test - supposedly applicable to both white and black prospective voters who couldn't prove a certain level of education but in actuality disproportionately administered to black voters - was a classic example of one of these barriers [to enfranchisement]." [29] 
or biological modifications or during a human lifetime, potentially including ongoing modifications and reversions to the original default ancestry without any enhancements. In such cases, "ancestry" would seem very artifactual. However, "ancestry" might still be relevant to self-determination for particular groups that have a shared group identity in addition to the identity of their individual members, such as an indigenous tribe or a disadvantaged caste, as will be discussed in Section 3 below. We may come to a similar conclusion regarding gender-related human enhancements as an additional example of "moderate" enhancements.

\subsubsection{Physical Enhancements-“Gender"}

For purposes of the discussion of voting in the United States, we will start with a binary definition of "gender" as male/female or woman/man to trace the historical lines drawn regarding voting rights, recognizing that such a narrow definition is not only overly simplistic it is harmful. As Professor Judith Lorber explains: “Today's gender paradox is a rhetoric of gender multiplicity made meaningless by a continuing system of bigendered social structures that support continued gender inequality." [31] ${ }^{11}$.

Professor Peter Singer offered this initial possible response to Thomas Taylor's satire of Mary Wollstonecraft's "Vindication of the Rights of Women" in 1972-“"A Vindication of the Rights of Brutes":

"Women have the right to vote, for instance, because they are just as capable of making rational decisions as men are; dogs, on the other hand, are incapable of understanding the significance of voting, so they cannot have the right to vote."12

For much of the history of the United States, there was no shared agreement that women were just as capable of making rational decisions as men. The right to vote in the United States, even prior to its formal construction through the United States Constitution, was a right for (white) male citizens only. According to the Preamble of the Declaration of Independence of 1776:

We hold these truths to be self-evident, that all men are created equal, that they are endowed by their Creator with certain unalienable rights, that among these are life, liberty and the pursuit of happiness. That to secure these rights, governments are instituted among men, deriving their just powers from the consent of the governed. [34]

The express reference to "men" was intentional, and the fact that it was not necessary to state "white" was because of the predominant view that people of color-whether indigenous, immigrant, slaves or "free Blacks" were not created "equal" to white men. "The founding generation's republican vision-that is, the vision of the propertied white males who monopolized political power and promulgated the Constitution-can be reduced without too much distortion to a handful of fundamental ideas. Moreover, the preservation of liberty in a confederated republic depended on limiting full political participation and legal personhood to propertied white men. The majority of the population-women, black Americans, the indigenous nations, the poor-would take positions decisively subordinate to that of propertied white men in the new constitutional structure [15]."

Denial of the right to vote based on gender was still allowed under the United States Constitution for another three decades after the right was given to Black males. In 1920, the Nineteenth Amendment to the Constitution was ratified. The Nineteenth Amendment specifies that: "The right of citizens of the United States to vote shall not be denied or abridged by the United States or by any State on account of sex." (emphasis added). Yet

11 This harm extends across species. See also the work of pattrice jones exploring the intersection of "speciesism and sexism at the heart of not only domestic violence and other forms of husbandry but also landlordism, racism, and 'ecophobia'" [32] (citations omitted).

12 Ref. [33] at 148-162. To be more accurate, this statement could be re-worded as "women are just as capable of making rational and irrational decisions as men are." In addition, we should not accept without challenge the assumption that "rationality" has a well-defined neutral meaning, nor that it is the sine qua non of voting. As will be suggested in Section 3, sympathy, empathy and emotional intelligence may all be equally valuable qualities, particularly for voters who have responsibilities toward non-voters who may be impacted by their vote. 
similar "informal disenfranchisement" occurred for women of color as for Black men, even after the passage of the Nineteenth Amendment. It was particularly easy to make such disenfranchisement legal because the wording of the Nineteenth Amendment did not affirmatively give women the right to vote. Instead, it was phrased to prohibit denial of the right to vote solely on the basis of gender. States continued to use poll taxes and other voter suppression tactics to keep women of color from voting. Asian American women who lacked citizenship as of 1920 were still not entitled to vote, nor were indigenous women. Even worse, the enfranchisement of white women at the expense of other women was intentional, not accidental.

What are the potential implications for moderate human enhancement and voting? In the near term, we can see that voter ID laws could easily be used to disenfranchise humans who changed their genders from male to female, or who were enhanced such that they appeared to be of a different gender than listed in their identification documents. For example, states that require government photo IDs, such as Georgia, can be daunting for transgender voters in the United States. ${ }^{13}$ Similarly, if gender modifications could be made at will, it could be even more challenging to meet legal voting requirements that incorporated some element of gender for identification.

In the longer term, if a person's gender could be changed prior to birth, and if a certain gender was more favored than another gender, we might see a voting population skew, over time, as more parents made the choice to only have children of the favored gender. This type of gender imbalance has already happened in certain countries. For example, as of 2018, men outnumbered women by 70 million in China and India (as a combined total). "A combination of cultural preferences, government decree and modern medical technology in the world's two largest countries has created a gender imbalance on a continental scale [37]." What would that mean for voting? Would all votes really be equal in the case of marked gender imbalance among the voters? ${ }^{14}$ What would the composition of Congress be if voting men outnumbered women substantially in the United States, due to human enhancements, or vice versa [39]? The votes (and concerns) of the gender minority could be of less interest to the candidates for election, and to the elected representatives - or of more interest if they were tiebreakers in close races, as happened with newly-enfranchised members of certain tribes in Canada during the 1800s [8]. As will be suggested in Section 3, in such a situation, it would be particularly important to consider and be responsible for the humans in the minority. Before addressing that area, however, we will push the boundaries of "human" by considering voting implications of extreme human enhancements.

\subsection{Extreme Human Enhancements and Voting}

Under our rough categorization, humans with extreme enhancements would typically be socially perceived as "inhuman" or "non-human" by humans who did not have similar enhancements. In such a scenario, it is not clear that the concept of "humanity" would still be meaningful as a method of drawing boundaries between conscious beings who have a right to vote- or to be entitled to representation if unable to vote directly.

Humans on a wider scale might elect to have extreme enhancements if they were safe, available, and particularly if they were reversible. Consider "Muffe" on a Danish children's show, who had horns implanted under the skin of his bald head [40]. Or Dennis Avner (also known as "Stalking Cat") who held a world record for the most permanent transformations to look like an animal [41]. These may be outlier examples now but the popularity of the "animal" filters on social media networks suggests that humans do enjoy

13 "The strictest voter ID laws require voters to present government-issued photo ID at the polls, and provide no alternative for voters who do not have one [35]." In addition, "each state handles gender and name changes differently. In Georgia, a judge has to approve a name change. To change a gender marker on your driver's license, you need a doctor's letter saying you've had gender reassignment surgery. The problem is that there are different kinds of transgender surgeries, and some trans people don't get any surgery at all [36]."

14 In the United States, for example, the 116th Congress from the 2018 Midterms had more women than ever. And yet women still were only $25 \%$ of the Senate and $23 \%$ of the House, when they represented approximately $51 \%$ of the United States population as a whole [38]. 
pretending to be animals if they can still retain some element of humanity. In other words, one key part of such filters is that the person still be recognizable as the "cute" animal. If similar physical enhancements were reasonably reversible, they might be adopted more widely and they might be more extreme, such that the enhanced human was seen as more animal than human. In that case, unless the laws were changed, it is reasonably likely that they would be denied the right to vote in the United States since animals do not have the right to vote. A similar result would likely arise if an enhanced human had so many inorganic enhancements that they appeared to be a robot versus a human being.

Another example of an extreme enhancement might be a "cultured brain," such as that discussed by Professor Kevin Warwick:

"It is quite possible to culture networks of dissociated neurons grown in vitro in a chamber. The neurons are provided with suitable environmental conditions and nutrition. A flat microelectrode array is embedded in the base of the chamber, thereby providing a bi-directional electrical interface with the neuronal culture. The neurons in the culture rapidly reconnect, form a multitude of pathways and communicate with each other by both chemical and electrical means. Although for most research in the field thus far, the neurons are typically taken from rat embryos, it is quite possible to use human neurons instead once sufficient connections have been made between the neurons so that, in research, the cultured brain is given a robot body with the ability to sense the world and move around in it" [42]

Should a "cultured brain" grown from human neurons be treated as a person having a right to vote if it was implanted in a human body versus a robot body? Should it even matter which body a brain is in? If a human being, say, for example, Dr. Stephen Hawking, was only able to communicate via neural implants (versus only via a single cheek muscle as was the case toward the end of his lifetime), would he be stripped of his right to vote because he no longer had a body that functioned? Alternatively, a sentient and sapient nonhuman consciousness ("Artificial Intelligence Plus" or "AI+") could reside (permanently or even temporarily) in a human body, such as via neural implants that connected the body to the AI+, which could also extend globally via Internet connections and a public or private cloud-based network. Such AI+ might not need to be physically constrained to a particular body-and could move between host human bodies at will or occupy more than one human body at a time, in constant communication. ${ }^{15}$ Another extreme enhancement example could be humans linked to form an extended consciousness, such as via Brain-toBrain Interface (BBI) technology, ${ }^{16}$ or even a "hivemind" of multiple enhanced humans (with both organic and inorganic based consciousness) ${ }^{17}$ who shared an interconnected consciousness, which might be given no vote, one vote, or the number of votes of the humans who were linked together.

Would such enhanced humans be entitled to vote? If so, why, where (in which country or countries), and how many votes would they have? Such extreme enhancement scenarios put pressure on the relevance of the human body to "voting". As Dr. Chia Wei Fahn has articulated for disabled bodies as interrogating existing normative standards of humanity, "technological growth and innovative design are now seen as having a unique influence regarding disability and posthumanism; disabled bodies are a 'dynamic hybrid' that is focused 'not on borders but on conduits and pathways, not on containment but on leakages, not on stasis but on movements of bodies, information and particles' that transcend corporeal boundaries and join the biological to the technological in posthuman embodiment."18

15 Such a scenario is described very powerfully in Ann Leckie's Imperial Radch science fiction trilogy, starting with Ancillary Justice [43].

16 One specific form of BCI development, Brain-to-Brain Interface (BBI), may lead to particularly novel social and ethical concerns. BBI technology combines BCI with Computer-to-Brain Interfaces (CBI) and, in newer work, multi-brain-to-brain interfaces- ... in which"real-time transfer of information between two subjects to each other has been demonstrated [44]."

17 Consider Professor Minoru Asada's hypothesis that a nervous system for pain sensation is necessary to shape the conscious minds of artificial (inorganic) systems [45].

18 Ref. [46] (citing Nayar, P.K. Posthumanism; Polity: Oxford, UK, 2014). 
For extreme enhancements, it is not clear whether "human DNA" should be required at all for voting rights, and if it is, in what percentage. Similarly, it is questionable whether the platform for the minds of such enhanced humans, whether neurons in the case of biological minds or silicon in the case of digital/software minds should be relevant to their voting rights.

Based on the history of discrimination in voting against those viewed as "other" as described above, a human who was enhanced to such an extreme level that they no longer appeared to be human at all-such as a full or hybrid inorganic or animal body, with varying transient embodiments, or with no embodiment whatsoever-would likely be denied the right to vote. It took Native Americans until 1924 to get the right to vote under federal law (and even until 1957 some states barred Native Americans from voting) [22]. Given this history, it seems unlikely that a cyborg with a human brain in a robot body (regardless of the source of the brain, birth brain versus cultured brain) or a "Frankenstein" with one person's brain implanted in another person's body would easily be given the legal right to vote, particularly if they were in the minority of the overall population and viewed as "freaks" or "less than human." 19 For example, in what might have been the first attack by non-enhanced humans on a human cyborg, Professor Steve Mann was wearing a system he called "EyeTap" physically connected to his skull. When he visited a restaurant in Paris, two employees allegedly tried to remove it from his head by force [47]. Given the prevalence of violent attacks (both in person and online) on those viewed as "other", such as transgender or gender-nonconforming individuals, as well as people who are physically or mentally disabled, it is likely that there would be efforts to prevent humans with extreme enhancements from voting, particularly if they were in the minority of the human population [48-50].

But what if certain enhancements, whether moderate or extreme, became the norm for the general population? In such a case, the non-enhanced might be (legally or practically) left behind when it came to voting.

\subsection{Disenfranchisement of the Non-Enhanced or Less-Enhanced}

In the case of either moderate or extreme enhancements, there is a risk that if such enhancements become prevalent among the existing population of voter, non-enhanced or less-enhanced humans could be legally and effectively denied the right to vote. For example, if moderate or extreme enhancements that allowed for a particularly convenient method of voting became ubiquitous for other reasons, then there could be effective denial of the right to vote for those who lacked the wealth or resources to have such physical enhancements.

\subsubsection{Accessibility Challenges}

What we can see from consideration of the physical methods of voting in the United States is that those who lack certain physical abilities that are considered "normal" (such as the ability to see or walk), or who lack access to certain technology or even the resources to physically get to a polling location, can be effectively denied the right to vote. We can expect the same result if human enhancements lead to a shift that allows votes to be cast by neural implants, or if other enhancements that facilitate voting become prevalent. Then the non-enhanced (or less-enhanced) humans may be perceived as disabled or less-abled and legally or practically denied the right to vote.

The United States Federal Americans with Disabilities Act of 1990 "provides protections to people with disabilities to ensure that they are treated equally in all aspects of life. Title II of the ADA requires state and local governments ("public entities") to ensure that people with disabilities have a full and equal opportunity to vote. The ADA's provisions apply to all aspects of voting, including polling places (or vote centers)" [51]. Similarly, under the Voting Rights Act of 1965 (VRA) election officials are required to allow a voter

19 This is a subjective judgment of course. Humans from several hundred years ago might think enhanced humans of today are "beyond humanity". 
who is blind or has another disability to receive assistance from a person of the voter's choice (other than the voter's employer or its agent or an officer or agent of the voter's union). But the reality is that despite these laws, such persons are less able to vote than the general population. ${ }^{20}$ In an audit conducted in 2020, more than 40 states were found to have "absentee ballot applications that were not fully accessible to millions of visually impaired voters and those with other disabilities [53]."

As Dr. Fahn has explained in a similar context of prosthetics and other technologies: "At present, biotechnological marvels remain a form of class consumption. Advanced technology is only open to those who can afford the purchase, causing people in one country to experience the same impairment differently, based on their socioeconomic status. The "have nots" and the "haves" will lead directly to an "ability divide" that is not only reflected by individuals, but sets a division on a global scale [46]."

Consider enhancements that allow humans to "vote" by using a neural implant and a secure wireless internet connection with their unique digital and biological signature (for authenticity). This is not so far-fetched as Prof. Warwick, one of the world's first cyborgs, described in his experiment involving a "basic form of telegraphic communication" between two human nervous systems. As Prof. Warwick explained:

"A volunteer assisted by having microneurography. Essentially, two very thin needles were pushed into the nervous system in their left arm. With this in place, we set up in the lab with a group of people around the volunteer and another group around me-we had a variety of different observers to oversee what we were doing. The volunteer and I were not able to see each other. We set the experiment up purely based on hand closures. When the volunteer closed their hand, I received a stimulating pulse on my nervous system, and the same happened vice versa. For me, it meant that my brain recognised the pulse. I shouted out "Yes" every time I felt a pulse, but only when I felt a pulse. Only the group around the volunteer could witness when they had closed their hand and when not. We achieved this with 100\% success - the same being true in reverse. What I found exciting was that as the groups were splitting up, I felt a couple of quick pulses one after the other. Subsequently, the volunteer confirmed that they had done this. It was a 'secret' message between the two of us, a new means of communication". [42]

Similarly, entrepreneur Elon Musk has long been a proponent of neural implants, such as those pioneered by Jan Scheuermann as part of the DARPA initiatives [54]. In 2020, Elon Musk's company Neuralink showed a demonstration involving a pig who had a braincomputer interface implanted that allowed a display of her real-time brain activity [55]. While the initial stated goal was to assist humans with paralysis or a serious illness, the "augmentation" of people who are healthy and without disabilities "is an obvious result," according to the Director of Implant Systems at Neuralink [56]. "It's being able to enhance our ability to interact with the world." [56] Similarly, an extended mind, as discussed in the work of Professors Dunagan, Grove and Halbert in "The Neuropolitics of Brain Science and its Implications for Human Enhancement and Intellectual Property Law", could also be considered an enhancement that could become the norm. ${ }^{21}$

20 "According to a 2017 report by the U.S. Government Accountability, "Voters with Disabilities: Observations on Polling Place Accessibility and Related Federal Guidance," roughly two-thirds of the examined polling places had at least one potential barrier such as lack of accessible parking, poor paths to the building, steep ramps, or lack of a clear path to the voting area. Although most polling places had at least one accessible voting system, roughly one-third had a voting station that did not afford an opportunity for a private and independent vote. The report also noted that Department of Justice guidance does not clearly state the extent to which federal accessibility requirements apply to early in-person voting. People with disabilities also continue to report barriers including a lack of accessible election and registration materials prior to elections, lack of transportation to polling places, and problems securing specific forms of identification required by some states [52]."

21 Ref. [57] Perhaps this "extended mind" is already becoming the norm in practice, even if not technically a "human enhancement" for purposes of this Special Issue, when one considers the expanded computational power and informational access available at any time $24 / 7$ to any human with a smartphone with internet access. Consider also Professor Fiorella Battaglia's proposal that an "extended mind" offers the potential of a new way to view the "mind-body" problem as an opportunity rather than a problem, emphasizing the epistemic difference between being a mind and being an extended mind in her forthcoming article in this Special Issue-“"Agency, Responsibility, Selves, and the Mechanical Mind" [58]. 
Such enhancements could become common because they offer more convenient lifestyle activities in addition to voting, such as electronic funds transfers, secure communications and hands-free use of all the apps and programs currently available on desktops, laptops, tablets and smartphones. If such enhancements became common for everyone who had the resources to purchase them, then access to voting could favor those who had such implants. In that case, unenhanced or less-enhanced humans could be effectively disenfranchised. We can see this happening already in the United States with respect to voting access. Traditionally, voting in the United States was conducted in person, at designated polling locations, for registered voters only. This has shifted to a greater percentage of mail-in ballots, and that shift was already occurring even prior to the pandemic of 2020 . Voting patterns in the United States reveal that wealthy voters are taking greater advantage of the ability to cast votes by mail ${ }^{22}$ [53]. It seems reasonable to anticipate that there will be a shift to computer voting in the future, and in that case voters who are poor and lack computer and internet access could be less able to vote. Voters with few resources may not have reliable addresses in order to be able to vote in person or by mail—or may not have access to printers or scanners to submit applications to vote by mail. Voters who are in poverty and/or have caregiver responsibility for friends or relatives may not be able to wait in long lines or to drive long distances to be able to cast ballots in person.

In addition to accessibility challenges, enhanced or non-enhanced/less-enhanced humans may also be effectively disenfranchised due to language barriers.

\subsubsection{Language and Communication Barriers}

With the click of a button, anyone with access to the Internet can easily translate a meaningful amount of the content into another language, even if the translation is imperfect. It is not a stretch to imagine that an enhanced human, such as via a neural implant or a genetic enhancement for linguistic ability, could readily speak and read a large number of languages, particularly those for which online translations are accurate. However, such rapid translations are not available for the vast majority of languages spoken in the world currently. ${ }^{23}$ The importance of using a language that voters can understand, and the impacts of the failure to do so, cannot be underestimated. ${ }^{24}$ Moreover, humans with extreme enhancements could "speak" new languages or even communicate in new ways that would not be intelligible to humans without similar enhancements. If such new languages became the "official" languages for voting, it could effectively disenfranchise the humans without such enhancements.

The choice to recognize a language as an "official language" is itself a decision that makes meaningful participation in government and voting more difficult for those who do not speak and read the official language (or languages) fluently. In many countries in Africa, the official languages may be French or English even though those are not the languages most widely spoken by the residents of such countries. In the European Union, for example, English, French and German are given preferential treatment as "procedural" languages although there are twenty-four official languages. Irish was only given the status of an official language in 2007 and was temporarily derogated through 31 December 2021 [62]. The fact that we face this challenge currently is an indicator that it should not be ignored in considering new languages that could be introduced via human enhancements.

22 "Among the obstacles for poor Philadelphians: Lack of stable housing makes it difficult to depend on the mail and know which address to provide when applying for a ballot to be mailed weeks or months later. Those with limited English proficiency have difficulty navigating the vote-by-mail process, and governmental voter outreach can miss them. Lack of internet service or home computers can complicate requesting ballots or finding key information about them [59]." In addition, a "2020 report by Native American Rights Fund determined that some members of the Navajo Nation must travel 140 miles roundtrip for postal services. Many do not have access to personal vehicles or public transportation to get them there [60]."

23 Google Translate purports to support over 100 languages, out of approximately 7000 languages spoken globally. "Odia, the official language of the Odisha state in India, with 38 million speakers, ... has no presence in Google Translate [61]."

24 An example from the Canadian period of enfranchisement and disenfranchisement illustrates that the challenges of different languages is not unique to any particular country or region. In the 1800s, one chief grew so frustrated by the use of English at a particular Council of tribes that he "led a break away council with other northern bands" and was "only lured back with the promise of an interpreter [8]." 
In enacting requirements to provide certain materials in additional languages as part of 1975 amendments to the Voting Rights Act, the United States Congress recognized that "Through the use of various practices and procedures, citizens of language minorities have been effectively excluded from participation in the electoral process. Among other factors, the denial of the right to vote of such minority group citizens is ordinarily directly related to the unequal educational opportunities afforded them resulting in high illiteracy and low voting participation. The Congress declares that, in order to enforce the guarantees of the fourteenth and fifteenth amendments to the United States Constitution, it is necessary to eliminate such discrimination by prohibiting these practices, and by prescribing other remedial devices." 25 Applying this goal to enhanced and non-enhanced/less-enhanced humans, if certain current or new languages became dominant, a meaningful right to vote would require, at a minimum, that translations be made easily available for the less dominant languages.

A similar additional potential cause of disenfranchisement might be if enhanced humans had such dramatically increased cognitive ability levels that it became practically impossible for the non-enhanced, or less-enhanced to "read" and comprehend the ballots even if they were reasonably fluent in the language itself.

\subsubsection{Cognitive Ability Requirements}

Cognitive enhancements, such as genetic cognitive enhancements via genetic engineering or embryo selection, pharmacological substances, Transcranial Magnetic Stimulations or Transcranial Direct Current Stimulation, or other techniques developed in the future, ${ }^{26}$ could become a common method to increase the intelligence of humans before birth or other modifications could be made after birth to the same purpose. In such a situation, it might become normal to include extremely lengthy and complex voting information on the ballot, ${ }^{27}$ or even ballot questions themselves (at least in states where ballot questions were permitted). Non-enhanced (or less-enhanced) humans could be unable to even decipher such questions at the polls. If they were not sufficiently enhanced due to lack of financial resources, then it would also be unlikely they would have access and time to peruse such ballot questions in advance. ${ }^{28}$ Ballot questions can be challenging currently even for highly educated and intelligent non-enhanced voters. If the "normal" enhanced human had the ability to visually access extensive background on a ballot proposition by visually looking at the equivalent of a "QR code" or through the internet via neural implant, then the ballots might not include the written summary at all, for example to save printing costs and for efficiency. Anyone who lacked the necessary enhancement(s) might not have the ability to obtain such details easily. In an extreme case, they might not even know what they were voting about at all.

Parents in poverty might, at least hypothetically, be more willing than wealthy parents to undertake intelligence or other enhancements for their unborn children even when they were risky. For example, as discussed by Professor Marcelo de Araujo, in initial research by the SIENNA Project, it appeared that "Scientifically and technologically developed countries are not especially supportive of research on human enhancement technologies....

25 For a determination of which minority languages would be covered - see the Federal Register [63]. One goal of the amendments was to clarify coverage of certain racial and ethnic minorities, including members of the "Hispanic" or "Latino" population "who had suffered discrimination in the political process, but whose group status under the law remained uncertain" and "by self-designation or by ascription, often eluded clear racial categorization and transcended strict racial labels such as 'black' and 'white [64].'”

26 Ref. [65] The work of Professor Nicole A. Vincent and others on neurointerventions and the law is also very relevant to any consideration of cognitive enhancements [66].

27 For example, ranked-choice voting has been challenging for many voters to understand. "Although no federal constitutional arguments have prevailed in Maine or in any of the other litigation around the country, opponents have argued primarily that it violates equal protection (one person, one vote) and due process (too confusing). Opponents generally attack [ranked-choice voting] on the grounds that it is too confusing and too costly. It requires voters to understand how the votes will be cast and counted, and then to vote accordingly [67]." Future possible voting methods, particularly those developed with the input of a diverse group of enhanced and non-enhanced humans as outlined in Section 3, could, at least in theory, be more complicated by one or more orders of magnitude.

28 An extremely lengthy and complex detailed "summary" of Ballot Question \#1 was offered for voters in Massachusetts in 2018 [68]. 
Brazil, South Africa, and Poland were most supportive, while the Netherlands, Germany, and France were least supportive of cognitive enhancement technologies [65]." While no definitive conclusion can be reached without a deeper analysis, this disparity at least suggests that it is possible that wealth disparities (either individually or at a country-level) might potentially correlate with the level of support for cognitive enhancement technologies. As one possible example, a positive view of cognitive enhancement technologies, such as by genetic engineering or embryo selection, may, at least in part, be influenced by the desperation of poverty.

What this situation tells us about voting is that if, in the future, the "norm" for the general population becomes humans with physical and/or mental enhancements that make it easier for them to vote through certain processes, then people who lack such enhancements may be effectively deprived of the right to vote unless accommodations are made.

With these examples in mind, it is important to consider a possible ethical theory that could be used as a framework to protect both enhanced and non-enhanced humans from being disenfranchised, to the extent possible.

\section{Discussion-Human Enhancements and Voting-Responding to the Appeal of the Other}

"The will of all beings, and responsibility toward all beings (whether voting or nonvoting), shall be the basis of the authority of government; this will, and responsibility, shall be expressed through universal and equal suffrage (directly and/or through representatives) or through such other process and method as may be developed and ratified with the universal and equitable participation of such beings."

—Draft, proposed Declaration of Rights and Responsibilities of Beings

In Section 2, we considered the phenomenon of voting and particularly how past experience might be relevant for enhanced and non-enhanced humans in a world where human enhancements, whether moderate ("still human") or extreme ("beyond human" or "non-human") were more common. It seemed likely that, based on the history of discrimination in voting rights and disenfranchisement of those deemed "other" or "lesser", long-established patterns of discrimination could impact both enhanced humans and, if those with enhancements became dominant, those without similar enhancements. In addition, distinctions based on ancestry, gender, and even embodiment itself would likely become meaningless artifacts, if they ever had meaning at all, particularly if such characteristics could be changed prior to birth and /or at will—either permanently or temporarily-at any time during the (potentially greatly extended) lifetime of an enhanced human.

In this Section 3, we will explore one possible philosophical framework for votingan ethics of human rights as outlined by Loidolt that is extended to cover humans with extreme enhancements who may no longer be viewed as "human" by those without such enhancements-as well as to cover humans who may be viewed as so primitive and irrational that they are considered to be "less than" human by the future enhanced humans. ${ }^{29}$ Such an extension would admittedly broaden Loidolt's already inclusive framework. However, the goal would be to preserve the core elements of the framework, including retaining the recognition of the impossibility of truly understanding and speaking for the "other." In Citizen Cyborg, Professor James Hughes predicted that "the emerging 'biopolitical' polarization between bioLuddites and transhumanists will define twenty-first century politics" [70]. For purposes of this analysis, it is not necessary to predict when, or if, such polarization will in fact occur, but it is important to recognize the possibility of different levels of power, and perspectives, between the enhanced and the less enhanced or non-enhanced.

After a brief introduction to Loidolt's theory of engagement, we will consider how it could translate to universal suffrage for all humans-enhanced and non-enhanced-

29 Much as humans of the 21st century questioned whether Neanderthals were a separate species despite interbreeding with Homo sapiens [69]. 
regardless of whether they are even still viewed as being human at all. Such an extension could include, for example, all "living" beings and all "conscious" beings as having rights and responsibilities to other beings. In attempting to provide support for this possible extension, we will consider specific criteria that may no longer be appropriate as voting requirements, including "reason" /"rationality" (which potentially impacts restrictions based on gender and age, for example), and physical geographic location within certain political boundaries. We will also consider scenarios where certain groups have an indirect voice through representative voting, in lieu of - or in addition to-direct voting. Finally, applying this extended version of the engagement-based ethical model, we will propose that the entire framework and legal and social structure of what "voting" means should be itself designed with the broadest possible participation, rather than dictated "from the top down." In other words, the humans who have the power at a particular period in time, whether locally, nationally, regionally or globally, cannot legitimately dictate what is best for future enhanced or non-enhanced humans or even for humans who otherwise are disenfranchised or were excluded from participation in the design of the architecture of governance. Such "others" (current or future) should have a voice in the design of the governance structure, and whether and what voting should mean, in order for such structure to have legitimacy. If they were not able to do so originally, there should be periodic opportunities for re-design and re-ratification.

\subsection{A Brief Introduction to an Extended Theory of Engagement}

One potential theory of engagement that can be applied to a world of enhanced and non-enhanced humans is offered by Loidolt ${ }^{30}$ [1]. By shifting the focus from a set of indispensable needs to the core responsibility of meeting such needs through an analysis of the structure of subjectivity, Loidolt outlined two themes that could serve as guidelines for an ethics of human rights in a theory of engagement, which we can extend to voting and human enhancements. The first theme emphasizes the transcendental importance of legitimization and justification in a meaningful world. The second theme seeks to "face the appeal of the other" and determine what is "right" "from a phenomenological first-person perspective instead of the classical 'objective' third-person perspective of reciprocity" ${ }^{\prime 31}$. Loidolt contends that the process of constituting the world is a priori occurring in a context of legitimizing intentionality. Specifically, "the meaning that something is 'right' or has 'a right', is not something that is perceived, but something that is achieved through passing a judgement: By judging something, by the means of implementing a norm or any measure, the meaning of 'right' or 'a right' originates as the formal expression of an 'accordingness.'"'32

30 Other possible ethical frameworks would be interesting to explore and likely would be fruitful for the analysis of voting rights and human enhancements, such as Professor Christine Korsgaard's Kantian ethical analysis of duties of humans to animals [71,72]. The work of Professor Simone Goyard-Fabre in combining an approach from Husserl's phenomenology with a Kantian analysis would also be relevant due to the deeply "legal" nature of the analysis of voting rights. Professor Maria Golebiewska provides a thought-provoking analysis in this area [73]. Another interesting framework to consider for voting rights could be Ernst Knapp's philosophy of technology, as proposed by Battaglia as a possible way to look at the "mind-body problem" in the context of a human-machine hybrid "extended mind" by using the "mechanical mind" as an explanatory device [58].

31 Ref. [1] at 3.

32 Ref. [1] at 7. 
This theory of engagement is a much stronger version of the suggestion made by Professor Chris Hables Gray in Cyborg Citizen: "Along with the realization that no totalizing theory explains everything is the corollary that a number of different perspectives together are capable of creating a better model of reality than any one point of view" [74]. Under Loidolt's framework, there is no utilitarian analysis of what is "better" (and no objective third-person "reality" to be modeled). Instead, the participation of others and consideration of their views is itself necessary for legitimization and justification in a meaningful world, even if the end result might later be deemed "worse" under a particular utilitarian ranking model than the result that would have been reached without their participation (assuming, hypothetically, that an accurate empirical evaluation was possible).

Under such a theory of engagement, there is an "intersubjective community of communication" and "being receptive as such" makes humans, as conscious beings, "answer [the appeal of the "other"] in a category of legitimization." Extending this theory to the right to vote and human enhancements, we will ask how, in a world of enhanced and non-enhanced humans, an ethical enhanced or non-enhanced human should answer the appeal of the "other" in the context of the right to vote. In doing so, we will follow Loidolt's guidance and treat "consciousness" not as a "secluded sovereign entity" but instead as "openness as such." ${ }^{33}$

\subsection{Universal and Equal Suffrage for Enhanced and Non-Enhanced Humans}

As we look toward the future, we can draw inspiration from the response to the horrors of World War II, in which approximately 6 million Jews ${ }^{34}$ [75] were systematically murdered by the Nazis. Victims included approximately one million children and teenagers. "Thousands of Roma children, disabled children, and Polish Catholic children were also among the victims. Like their parents, they were singled out not for anything they had done, but simply because the Nazis considered them inferior" and sub-human [76]. After World War II, the Universal Declaration of Human Rights ("UDHR" or "UN Declaration") was adopted. The UDHR was a collective shout of optimism that, by coming together, there would never be a repeat of such atrocities. The dream was that humans could live together in peace and harmony. While recognizing that such goals were not achieved, ${ }^{35}$ we can nevertheless seek inspiration from that work in the context of voting rights and enhanced humans and hope for further progress, even if it is incremental and imperfect.

For the current analysis, we will focus on Article 21(3) of the UDHR [2], which states:

(3) The will of the people shall be the basis of the authority of government; this will shall be expressed in periodic and genuine elections which shall be by universal and equal suffrage and shall be held by secret vote or by equivalent free voting procedures.

In extending the right to vote in a world of enhanced and non-enhanced humans, we will modify Article 21(3) to remove the term "people" and replace it with the more inclusive term "beings". Thus, for purposes of discussion of voting rights in such a context, one possible way to re-frame Article 21 is as follows:

"The will of all beings shall be the basis of the authority of government; this will shall be expressed through universal and equal suffrage."

With the reference to "people" changed to "beings," this framework could be used for extreme human enhancements, where the enhanced human may no longer be recognized by non-enhanced humans as "human" at all, as well as for more moderate enhancements, where the broader community may be oblivious to important differences because they are not readily perceptible or detectable absent invasive testing. Similarly, it would apply to non-enhanced or less-enhanced humans who might be viewed by future enhanced humans

33 [1] at 8-9.

34 According to the testimony of Dr. Wilhelm Hoettl in the Nuremberg Trials in 1945 regarding a statement made to him by Adolf Eichmann, Chief of the Jewish Section of the Gestapo: "Approximately 4 million Jews had been killed in the various concentration camps, while an additional 2 million met death in other ways, the major part of which were shot by operational squads of the Security Police during the campaign against Russia" [75]. 
with extreme enhancements as "sub-human" or otherwise "inferior". In the ethical model we seek to extend to voting and human enhancements, "justice" is "not a self-assured calculation with symmetrical portions of free will, but an urgent conceptual reaction to an overwhelming appeal that can never be adequately responded to." ${ }^{\prime 36}$ Extreme enhanced humans would still have a right to vote as long as they were viewed as "beings" meaning, in a very broad definition, that they were either "living" or they were "conscious". Similarly, non-enhanced/less-enhanced humans viewed as "other" or "lesser", would also have a right to vote as "beings".

In the following sections, we will seek to provide some support for such an expansion, including considering arguments that would retain the requirement of "humanity" for voting rights and therefore could exclude humans with extreme enhancements from voting. Finally, we will acknowledge the concern that an expansion of legal rights to votes broadly to all enhanced and non-enhanced humans could contribute to an unintended consequence that those who lacked power currently could be disenfranchised or otherwise harmed. Since such a harm is possible based on past experience with discrimination against the "other", we will suggest that, under the extended ethical framework being applied, such humans should be involved in any decisions regarding their enfranchisement and indeed the entire voting process and very framework of governance.

\subsection{Casting a Broad Net for the Definition of "Human" in the Context of Voting}

By intent and express language, the Universal Declaration of Human Rights covers the rights of "human beings." Under Article 1, "All human beings are born free and equal in dignity and rights. They are endowed with reason and conscience and should act towards one another in a spirit of brotherhood." However, in trying to meet the appeal of the "other" (and indeed the multitude of "others") in the context of voting and human enhancements, we propose to reject "humanity" as a litmus test and instead cast a wider net in defining the "other" as any living or conscious being. ${ }^{37}$ We will "recognize the urgency that demands" the impossible and commit to the "rights of the others, ... to equality, dignity etc., with the insight that [equality, dignity, etc.] will have been dependent on that commitment" and with "awareness of the imperfection and urgency of the case, thus alertness to the disturbing, responsivity to and responsibility for it, while being aware that [the disturbing demands of the others] can never be fully incorporated; and finally openness to that universality in progress (or universality to come) that keeps being constituted from the outside." 38 In this context, "disturbing" may perhaps be understood to mean both changing/disrupting the status quo as well as troubling/unsettling to the being who is called to respond to the appeal of the "other".

Under this extended ethical framework of engagement and under an expanded Heideggerian approach, enhanced humans and non-enhanced humans would all be "beings" entitled to certain rights but also with certain duties and responsibilities towards others.

"Man is not the lord of beings.

Man is the shepherd of being.

36 Ref. [1] at 12 (referencing the work of Emmanuel Levinas, 1978).

37 "Social robots should not be regarded as proper objects of moral concern unless and until they become capable of having conscious experience. While that does not entail that they should be excluded from our moral reasoning and decision-making altogether, it does suggest that humans do not owe direct moral duties to them." [78] Under an extended ethical theory of engagement and the new Declaration of Rights and Responsibilities of Beings toward which this Article on voting rights is intended to provide a stepping stone, the goal is to be as inclusive as possible. Ideally, all living beings, whether "conscious" or not (e.g., plant-based life or a human who is in a coma), and all "conscious" entities should be included in the definition of "Beings". Full articulation of the meaning, scope and boundaries for such an inclusive definition, as well as the philosophical basis (or bases) will obviously require significant work. A Kantian perspective of "personhood" and "identity" would be useful to consider, such as that presented by Professor Béatrice Longuenesse: "Kant's criticism of the paralogism of personhood opens the way to to substituting for the rationalist concept a rich and complex concept of a person as a spatiotemporal, living entity endowed with unity of apperception and with the capacity for automomous self-determination." [79]. 


\section{Man is the neighbor of being" ${ }^{\prime \prime 39}$ [80]}

Heidegger struggled with anthropocentrism, eventually concluding that "until we arrive at a fuller understanding of the nature of world, we cannot pass judgement on the ultimate legitimacy of his conception of the animal as poor in world. Only then can it be determined whether there is "poverty in the animal's specific manner of being as such", or if such poverty obtains only in comparison to Dasein" [82,83]. In our extended ethical theory of engagement, we propose that it is not legitimate to deprive any enhanced or non-enhanced humans of voting rights while we await a "fuller understanding of the nature of the world." Instead, we will value beings in the lower-case versus the "Dasein" of Heidegger (with Dasein meaning roughly a human being "there"-totally immersed in the world of other things-a "Being-in-the-world"). An essential element of such an equitable approach is an awareness that there is an inherent risk of error any time one being represents another being or purports to understand what another being wants or needs. Indeed, Heidegger may have underestimated the depth of the "Abyss" between humans while overestimating the depth of the "Abyss" between humans and animals. ${ }^{40}$ Thus, a sufficiently "full" understanding of the nature of the world, such as that contemplated by Heidegger, may be impossible to achieve. As Loidolt explained, we must try to "realize the intentional movement of reason towards complete legitimization: even if it cannot be achieved, legitimizing intentionality can not stop at an unjustified benchmark, but transgress it necessarily with critique ${ }^{\prime \prime 1}$.

Such an extended ethical approach of course requires explicitly rejecting the antisemitism and other arbitrary biases that permeated the philosophy of Heidegger-and Nietzsche-and seeking a commitment to respect for others. In his provocative concluding paragraph of his article in this Special Issue, Warwick draws from Nietzsche to speculate about a possible bleak future for non-enhanced humans: "The fundamental philosophy that underpins the concept of the future relationship between superhumans and humans comes straight from Nietzsche. We need to look no further than humans' present-day relationship with other animals. Humans cage them, destroy their habitat and treat them as captives, slaves or pets. Thus, if we look to the future, the best that a human could hope for might be that they become the pet of a superhuman." [42].

Surely we can hope for better than this. We can attempt to design an ethical structure of voting rights and responsibilities to reflect such aspirations while also considering the existing realities of imbalances in political power and other relevant factors. As an example, the brutal legacy of years of systematic discrimination has led to widely disparate income, education, health, medical treatment, access to housing, credit, incarceration, job opportunities and death (including killings by law enforcement agents) for people of color in the United States. ${ }^{42}$ Voters (and their elected representatives) should consider not only their own interests but also their responsibility toward other beings, particularly those who cannot vote or whose votes may "count" for less than those in power. While it is theoretically possible that an enhanced human might have the ability (and will) to control other beings without voting or control others in voting, we should not automatically assume that is what would happen. An enhanced human might also have greater compassion and empathy, as well as improved emotional intelligence such that they would not wish to use their power in that manner. Any human, with any level of abilities or power, is capable

39 Ref. [80] In applying any phenomenological approach that may have been influenced by the works of Heidegger, it is important to explicitly acknowledge the deep-rooted antisemitism in Heidegger's philosophical views. For a powerful rebuttal of the idea that Heidegger's antisemitism can be easily separated from his philosophical viewpoints, see Professor Donatella Di Cesare's work [81].

40 "Although at one time exploring the proximity between the human and the animal, Heidegger later claimed that an abyss separates the human from the animal." [84] at 110 (citations omitted).

41 Ref. [1] at 18.

42 For example, in 2017, the median net worth of Black residents in Boston was $\$ 8$ versus $\$ 247,500$ for whites [85]. Also, "Black female restaurant workers in Massachusetts make on average $\$ 7.79$ less per hour-including tips-than white men in the same positions, which amounts to 60 percent less" [86]. As just one example that discrimination and violence based on skin color is not limited to the United States, see an example from France [87]. 
of doing good or evil. Adolf Hitler was able to do great evil without enhancements, and Nelson Mandela was able to do great good without enhancements. Applying an ethical theory of engagement, the appropriate response to the possibility of a hypothetical future sociopath having tremendous power is not to abandon any path toward self-determination. We take that risk now - and likely that will be the case whatever form of government we establish for future enhanced or non-enhanced humans.

A more fundamental challenge to enfranchisement of "beings" than the spectre of a super-powered tyrant may be the view that humans are innately and metaphysically superior to all other beings. Such an objection could be based, for example, on the contention that there is inherently a hierarchy of species and that any broad approach that allows enhanced humans who are viewed as being more animal than human, more plant than human, or more computer than human to be treated as "human" upsets the proper hierarchy. The view that "pure" humans are of special and unique value higher than any other living being - whether conscious or non-sentient-is deeply entrenched in many widely-respected philosophical, scientific and religious frameworks. ${ }^{43}$ Someone who holds that view may well feel that a human who has an extreme enhancement (either prior to birth or after birth) is not a human at all, or is less-than human. In that case, the extension of the right to vote to such an enhanced human likely would be rejected as the extension of the right to vote to non-human animals and to plants or other life forms would also be denied. Such a rejection need not be made callously or with indifference to others. Representation alone, as outlined in Section 3 below, could be viewed as sufficient to respond to the appeal of the "other" even under an ethical theory of engagement. However, in this analysis we are pushing the definition of "other" to reach beyond "humans" in the context of extreme human enhancements. This is a fundamental difference in perspective. In order to support this expansion, we will consider some of the reasons typically given for excluding animals ${ }^{44}$ from having the same rights and responsibilities as humans, and express concern about their validity and the danger that they can be used as a proxy for improper discrimination (including against other humans). However, the core philosophical differences will not be reconciled in the analysis herein, and it is not clear that they are capable of reconciliation.

\subsection{A Provisional Rejection of Ranking Systems/Hierarchies}

One of the problems with any hierarchical approach, which is particularly acute in the context of enhanced humans, is that it is challenging to articulate meaningful ranking criteria that can withstand scrutiny and that do not naturally lead to individual humans being further ranked and excluded from voting. In addition to being pretexts for racism, sexism, classism, etc., ranking systems of the past have turned out to be factually false or absurd. For example, Plato felt that walking upright was a key distinguishing feature of humans. Darwin considered that bipedalism represented evolutionary advancement. However, it is difficult to see why walking upright is intrinsically a high value physical trait, or even that it is unique to humans. ${ }^{45}$ From a value perspective, is walking upright better than flying, running fast like a Cheetah, or having an extremely precise sense of smell like a dog? Why is one physical trait inherently better than another? Second, once one establishes any form of ranking criteria, there is a natural tendency to further rank within each category. For example, if a human cannot walk upright at birth, or at some point during their lifetime due to a physical challenge, are they no longer human or less

43 Also, in certain religions. For example, Genesis 1:26 “Then God said, 'Let us make humankind in our image, according to our likeness; and let them have dominion over the fish of the sea, and over the birds of the air, and over the cattle, and over all the wild animals of the earth, and over every creeping thing that creeps upon the earth.'" For an alternative interpretation, see the work of Professor Ryan Patrick Mclaughlin, who proposes that, under one credible reading of Genesis, "human dominion" should be "peaceful and other-affirming" [88].

44 Although the present ranking discussion focuses on animals, a typical reason given for excluding computers (even ones that can communicate in a manner that is difficult to distinguish from an actual human) is that they lack sentience. In other words, they are neither conscious nor self-aware.

45 "If an ape who stands upright (even with the help of a mobility device) can be seen as more human, what happens to humans who do not or cannot stand upright? Monkey-like posture was one of many simian characteristics used to dehumanize people of color, particularly people of African descent, from the seventeenth century on." [3] at 86-87 (discussing illustration from 1699 of an ape standing erect with a walking stick). 
than other humans at that point? If so, the famous physicist Dr. Stephen Hawking was not human (or was less than human) once he could no longer walk upright. Such a conclusion would not be acceptable even under the current version of the UDHR.

We will consider in more depth two other potential candidates as requirements for voting rights under the expanded version of UDHR and as potential justifications to retaining the requirement of "humanity" for voting rights for enhanced and non-enhanced humans-"reason" (also referred to herein interchangeably with "rationality") and "dignity". Both terms are used in Article 1 of the $\mathrm{UDHR}^{46}$ and are frequently used in ethical theories relating to differences between humans and others.

\subsubsection{Rejection of "Reason" /"Rationality" as a Voting Requirement}

As discussed above in the context of a history of discrimination, the "ability to reason" and "rationality" have often been put forth as a purportedly neutral and objective requirement for voting rights. Aristotle viewed humans as the only rational beings. If only humans are rational, and if rationality is essential for voting, then perhaps enhanced humans who are more animal than human, more plant than human, and/or more machine than human should be excluded from voting?

One problem with this approach is that the definition of "reason" or "rationality" is key and it is not automatically clear what such terms mean in the context of voting rights and responsibilities of enhanced and non-enhanced humans. Does "rationality" mean the ability to think logically? If so, at an advanced level such as Aristotle demonstrated? If we have enhanced and non-enhanced humans, should all voters be tested on basic logic and, if they fail, be disenfranchised? If only some voters are tested, then the potential for discrimination based on improper categories is high. Also, why should logical thinking be of greater importance than creative thinking or compassionate thinking when it comes to voting? Should a human who excels at logical thinking or mathematical computational abilities be valued more than another human who cannot perform as well? When will the testing for such abilities be administered, by whom and on whom? Or, is "reason" only an ability to understand cause and effect in one's daily life? Many animals can understand cause and effect. Otherwise they could not be trained by humans. ${ }^{47}$

Returning briefly to the example of gender that was discussed in Section 2 above, we can perhaps uncover even more that may be relevant to the potential requirements of "rationality" or "reason" in voting in a world of enhanced and unenhanced humans in examining the argument that "Women have the right to vote, for instance, because they are just as capable of making rational decisions as men are." ${ }^{8}$ This statement assumes that "rationality" is part of the act of voting, when observation of the phenomenon of voting reveals that "[t]he separateness of vote and decision decouples any pretence of rationality from the decision. It makes little sense to talk of rational democratic decisions, although we may approve of decisions for other reasons. Nor will you find support for rationality within the events leading to the decision. The naïve account of events is that the participants think about each specific decision with the penetration of Socrates and stand by their rationally derived conclusion with commendable integrity. Observe voting and you will see that the vast majority of decisions are preceded by inadequate and contradictory thought, much of it around matters that are peripheral to the specific content of the decision to be taken.

46 "All human beings are born free and equal in dignity and rights. They are endowed with reason and conscience and should act towards one another in a spirit of brotherhood."-UDHR Art. 1 [2].

47 And as many people with pet cats and dogs can attest, animals also can train their humans to behave in a manner desired by the animal at a particular time, in response to a particular prompt from the animal.

48 See Singer's work in [33] at 148-162 (describing an initial possible response to Thomas Taylor's satire of Mary Wollstonecraft's "Vindication of the Rights of Women" in 1972- "A Vindication of the Rights of Brutes"). 
With equal claim to rationality politicians may determine to vote in accordance with their constituents' wishes, higher economic theory, or their perceived personal self-interest." 49

Also, are all men who have the right to vote capable of making "rational" decisions? Should "rationality" even, in a naïve account of events, be an essential condition for having a right to vote, versus empathy for others, compassion, generosity or some other quality or quantity? If it were possible to enhance humans so that they were able to make better moral decisions, [90,91] should the votes of such enhanced humans be given greater weight? At a more basic level, what is the meaning of "male" or "sex" in the context of voting, given that one hopes that genitalia are neither involved in nor displayed when a being votes? Similarly, the argument that "dogs, on the other hand, are incapable of understanding the significance of voting, so they cannot have the right to vote" assumes that it is an essential requirement to "understand the significance of voting" in order to have a right to vote [33].

In addition, "rationality" has been used as the basis to deny the right to vote to those under a certain age. In the United States, the right to vote in federal elections was lowered through the Twenty-Sixth Amendment XXVI-which changed the minimum voting age from 21 to 18 years. Are humans under 18 not "rational"? One argument for why those under 18 do not have the right to vote is that their brains have not developed to the point that they can weigh risks "rationally" with an "appropriate" level of conservatism [92]. But people under 18 are part of the population and have good reason to be concerned about choices made by members of an elected body who do not reflect their views and interests. Also, as described above, based on the past and current use of testing for intelligence or knowledge, we should be very skeptical that such cognitive capacity requirements would be applied in a non-discriminatory manner when enhanced humans and non-enhanced humans are involved. If a human could change their physical age via enhancements—at will-and/or increase their cognitive capacity at will, then it is not clear that their actual date of birth would be particularly relevant to their right to vote (if it ever was relevant). Potentially, "age" requirements for voting could be eliminated, particularly in a world where enhanced humans were common. ${ }^{50}$

Fundamentally, is not clear that voters really need to "understand the significance" of voting in order to have a right to vote in a theory of engagement that requires responding to the appeal of the other. "A part of the myth of democracy is that it requires higher thought processes and rationality" [89]. To exclude an entire class of enhanced or non-enhanced humans on the ground that they could not "understand the significance of voting" could easily lead to other exclusions that have been used to discriminate in the past (and in the present), such as a requirement that voters have at least a certain level of formal education or that applicants for citizenship, and therefore the right to vote, pass certain tests. ${ }^{51}$ For example, American suffragist Elizabeth Cady Stanton argued that (white) educated women were more deserving of the vote than "ignorant" men, including many formerly enslaved people, working-class people and immigrants [93]. Intentionally drawing on racist stereotypes, she explained: "Think of Patrick and Sambo and Hans Yung Tung, who do not know the difference between a monarchy and a republic, who can not read the Declaration of Independence or Webster's spelling-book, making laws for Lucretia Mott, Ernestine L. Rose, and Anna E. Dickinson [94]."

Similarly, by this argument, cognitively enhanced humans might perhaps deny the right to vote to those without enhancements. In rejecting artifactual and frequently discriminatory distinctions such as "rationality" and "reason", we propose that even enhanced

49 Ref. [89]. An alternative model of representation is offered by the Japanese Constitution, where Members of Congress are given the role of "representatives of the whole citizenry", which is understood to mean (1) "a congressman/woman is not a representative of each electoral zone, but a representative of all Japanese nationals" and (2) "he/she is not bound by voters in each electoral zone or by his/her supporters' organization." Ref. [9] at 35 (discussing Article 43(1)).

50 One of the obvious enhancements that is currently sought out via plastic surgery and cosmetics is to change one's age.

51 Should voters be required to pass a test for drug or alcohol impairment on the day they cast their vote? Screening for mental illness? If so, which types of mental illnesses? Depression? Who would decide and how would adminstration be executed in practice in a non-arbitrary and non-discriminatory manner? 
humans who are seen as more animal than human, more plant than human, more machine than human or not even permanently embodied at all (or changing between such forms at will), should still have a right to vote.

In considering voting rights in a world of enhanced and non-enhanced humans, it is critical to strive to apply the rights and responsibilities of beings carefully, with due consideration of systematic injustice or harm that can result from stereotypes of from treating any beings or group of beings as "other" or "lesser." The way that a particular right is applied to a particular being in a particular context can and, in many cases, should vary based on the nature of the being but any variations should be equitable and grounded in respect for the fundamental autonomy of each being. Respect for "dignity" of humans (enhanced and non-enhanced) is a core part of the proposed extended ethical framework under consideration. We commit to the "rights of the others, commit to equality, dignity etc., with the insight that [equality, dignity, etc.] will have been dependent on that commitment." 52 However, that does not mean that some assessment of "dignity" of any individual human or a particular type of enhanced or non-enhanced human is a requirement for voting rights. ${ }^{53}$

\subsubsection{Rejection of "Dignity" as a Voting Requirement}

Moving beyond "rationality" or "reason", should "dignity" instead be a key ranking requirement? If so, what do we define as "dignity"? Who defines it? Why should we assume in advance that animals do not have any dignity or that if they do their dignity is less than that of a human? Or, in the context of human enhancements, why would we predict that there is some threshold at which an enhanced human is "more animal than human"54 or "more machine than human" and then are no longer humans at all? ${ }^{55}$ Who would determine when such a threshold was reached and how would they do so?

The definition of "dignity" should not be based on physical abilities or it is just an extension of bipedalism. A human being who is in a wheelchair and needs assistance to go to the bathroom, to dress and undress themselves, and to feed themselves is not less "dignified" than another human who can engage in such activities without obvious assistance. As Taylor convincingly explains, the "independence" and self-sufficiency of those viewed as "able-bodied" is a myth [3]. Interconnectedness and mutual dependency on other beings (humans and animals) is the true norm. Even people who are not viewed as "disabled" need assistance from others to engage in all of these activities. Unless someone is living "off the grid" and hunting for their own food with a weapon they made themselves, skinning it with a knife they made themselves, cooking it on a fire they made with wood they gathered, making their own fabric and clothes, and building and maintaining their own sewer system, they are benefiting from the extensive help of many other humans on a daily basis (and they are highly and obviously dependent on animals, plants and nature). Often the others upon whom we depend are an invisible population of those viewed as "lesser" - such as immigrant agricultural workers in the United States and the Dalits in India who perform the dirtiest jobs such as cleaning sewers and taking away dead animals [97]. Are they less "dignified" in a ranking or hierarchy? If so, is that because of something innate or inherent in the world or because the societal choices have been made systematically for hundreds of years, both intentionally and unintentionally (by people with the privilege of being allowed to be oblivious to the needs of others who are less powerful), to treat such people as "lesser" and to make their daily life more difficult than necessary, such as by designing curbs to be inaccessible to wheelchairs versus sloped, or by

52 Ref. [1] at 13.

53 As discussed in Section 3 below, representative voting is an available option, such as for a human that is mentally incapacitated to such a severe degree that they are incapable of expressing their wishes, or is unconscious (for example in a coma).

54 This can be especially challenging when humans already have substantial overlap with animals, as outlined by Professor Jacques Derrida [95].

55 For example, Professor Francis Fukuyama expresses concern that one of the potential effects of biomedical advances is that humans may be altered beyond recognition and this could have negative effects on the belief that human beings are equal by nature [96]. 
preferring stairs versus ramps in building designs? These choices were not necessary for any reasons related to the "natural" world.

Should "dignity" instead be based on caring for others and having compassion? If that is the case, many animals have demonstrated that they care deeply and intensely for others, including members of their own species and of other species. For anyone who has never seen a pet mourning the loss of an owner or companion, there are a multitude of examples of animals showing compassion and care for others, including, as just a few examples, dogs comforting humans who are struggling physically and/or emotionally, elephants visiting the home of a conservationist who had worked to help them after his death, ${ }^{56}$ or Koko the gorilla who could communicate with humans through sign language and grieved when her companion cat died. "[W]hen [her companion kitten] died in 1985 after being struck by a car, Koko pretended she didn't hear her handlers for about 10 min after they told her the news. Then, she started whimpering. She signed 'sleep cat' by folding her hands and placing them by the side of her head. Researchers gave her a stuffed animal, but she wouldn't play with it and kept signing: 'Sad'" [99]. Recognizing that animals do have compassion and caring for others does not mean we should assume that they are the same as enhanced or non-enhanced humans. ${ }^{57}$ Such a view would be inconsistent with the ethical framework of responding to the appeal of the "other" because it would deny that there was anything new or different that the "other" might tell us or include in their appeal. Instead, recognizing that animals have "dignity" (if that is defined as caring or compassion for others, for example) means that it is not ethical to deny the right to vote to enhanced humans even if they are considered to be "more animal than human" or to deny the right to vote to non-enhanced (or less-enhanced) humans if, in the future, humans with extreme enhancements considered such beings to be "sub-human."

Article 1 of the UDHR sets out the overarching principle that "All human beings are born free and equal in dignity and rights. They are endowed with reason and conscience and should act towards one another in a spirit of brotherhood." This should most properly be read as a normative or prescriptive, aspirational statement rather than a reflection of some objective reality. It is difficult to imagine any country or even any city or town in the world in 1948 where all humans were actually born with equal rights. The drafters of the UDHR were certainly aware of differences in rights of humans. We have seen from the examples in Section 2 above that pretending that every human is, in practice, equal (and is treated equally) in voting rights and ability to vote is to deny the existence of racism, classism, sexism, ageism, caste systems etc. Voting rights that are granted and designed in denial of the impacts of systemic racism, for example, will fail in practice to achieve anything close to "equal" votes.

In extending the right to vote in a world of enhanced and non-enhanced humans, we have modified Article 21(3) to remove the term "people" and replace it with "beings." For someone who views humans as intrinsically higher than all "others", or for whom only humans should be ethically entitled to vote, then they might be willing to accept this expansion if the term "beings" is defined to require, in the context of human enhancements, only that the candidate for enfranchisement was at some point in time a non-enhanced human or descended from a non-enhanced human in order to qualify as a "being". Or they might reject the change altogether and insist that the right be limited to enhanced humans who are still genetically predominantly Homo Sapien based on their DNA. In other words, more human than anything else. However, this is not a truly satisfactory solution in the extended ethical framework of engagement. Such a distinction seems uncomfortably close to gender-based and ancestry-based biases such as a law prohibiting children from inheriting citizenship (and voting rights) from their mothers. This was the law in Iran until 2019 and is still the law around the world, where " 25 countries bar women from

56 "Nonhuman animals are amazing beings. Daily we're learning more and more about their fascinating cognitive abilities, emotional capacities and moral lives" [98].

57 For an additional approach, see the work of Professor Lori Gruen [100]. 
passing citizenship to children, while more than 50 have other discriminatory nationality laws such as those that, for example, permit only men to pass on citizenship to a foreign spouse," according to the United Nations High Commissioner for Refugees [101]. It also seems too much like a species-biased ${ }^{58}$ (and organic/biologically-skewed) counterpart of the so-called "Grandfather Clauses" used to deny the right to vote to former slaves and their descendants. As mentioned in Section 2 above, voting restrictions based on ancestry are often explicitly designed and enforced to disenfranchise those deemed "lesser" or "other" and privilege those who were already "grandfathered" in as voters. "The phrase 'grandfather clause' originally referred to provisions adopted by some states after the Civil War in an effort to disenfranchise African-American voters by requiring voters to pass literacy tests or meet other significant qualifications, while exempting from such requirements those who were descendants of men who were eligible to vote prior to 1867" [30].

The intended definition of "beings" in the revised Article 21(3) should extend to animals, plants, inorganic intelligence (such as AI+) and even extraterrestrial "beings" (if any existed and for some reason wanted to vote) who never were human and who never descended from humans. The core minimum requirements for qualification as a "being" under Article 21(3) definitely warrant a deeper consideration if they are expanded as intended to respond to the appeal of the "other" (defined broadly). However, for purposes of discussion as an initial proposal, the minimal requirements for voting could be "life" or "consciousness." If a being is either "living", even if unconscious or largely plant-based, or "conscious," including animals or an AI+ where the being might have no organic embodiment and could, for example, be sentient and machine-based, such a being would be entitled to a right to vote under our extended ethical framework. However, due to lack of consciousness or lack of communications abilities, such voting might, in practice, need to occur via a representative as discussed in Section 3 below.

In the ethical framework of engagement and responding to the appeal of the other, there is no search for a fixed objective third-person reality where one would measure "dignity", "reason," or "conscience" in order to determine if the "other" had the right to be heard, and if the being who was attempting to respond had a responsibility to do so. The goal is to intentionally "see" those beings who are "other" and "hear" their voices as much as possible, recognizing that any being (enhanced or non-enhanced) will inevitably not fully understand the views and needs of other beings in the same category (because each individual being is unique), much less those in a different category, but must nevertheless try to do so as it is better than the alternative. The result will be flawed and imperfect, but it has the potential to be more legitimate, from an ethical perspective, than the other path where beings are ranked based on certain traits that are difficult to define, potentially false and/or artifactual, and that is particularly the case when the highest valued traits typically turn out to be traits the being doing the ranking possesses.

\subsection{Potential Backlash against Humans Who Are Currently Disenfranchised}

One important possible objection to the approach of universal and equal suffrage for all enhanced and non-enhanced humans is a concern that broadening the definition of "beings" who have rights (and to whom other beings have responsibilities) may, in practice, dilute or diminish the current rights of those without power (or with less power), such as minority groups. One of the arguments made by those who opposed giving women the right to vote in the United States was that women would, in practice, lose the benefits of their "exalted" positions if they were given the right to vote, and they would, as a result, get less protection. ${ }^{59}$ The Nazis had strong animal protection laws and yet gave no such consideration to human beings they deemed as "lesser" or "other" [104]. Early Europeans

58 As Professor Alice Crary proposes, "the plain fact of being human is morally significant but the plain fact of being an animal is so as well." Ref. [102] at 122 .

59 "To man, woman is the dearest creature on earth, and there is no extreme to which he would not go for his mother or sister. By keeping woman in her exalted position man can be induced to do more for her than he could by having her mix up in affairs that will cause him to lose respect and regard for her [103]." 
used systems of classification to justify colonialism by "highlighting the human character of apes while emphasizing the purported simian qualities of Africans." ${ }^{\prime 60}$ In Canada, male members of certain indigenous peoples who were deemed "civilized" (in part by virtue of owning land but also, depending on the time period and the law, by passing a test showing they could read and write in English) were given the right to vote in 1886 in pursuit of an express goal of assimilation. This was opposed by certain tribal leaders, who correctly predicted that it would lead to increasing political division within their own nations, on political party lines, and ultimately a loss of sovereignty and further loss of land. In just over a decade, "as the franchise expanded, settler politicians expressed the growing popular racism that presumed Indians could never be civilized-at least not without the radical process of removing children to assimilate them at infancy into white society." ${ }^{\prime 61}$ As a result, in 1898 the right to vote was revoked for all "persons of Indian blood" (which was defined even more broadly than the definition of "Indian" men under the Indian Act). ${ }^{62}$ "Over the twelve years from the creation of the Indian franchise in 1886 to its revocation in 1898, the early Victorian dream of the transformation and assimilation of Indigenous peoples as respectable Christian subjects gave way to a cynical idea of segregation under the permanent regime of the Indian Act. (Only children would be excepted under a radical new program of forced separation and assimilation in residential schools.)" ${ }^{\prime 63}$

It is impossible to guarantee - or even predict—a particular result at a particular time in a particular country or region, or the world as a whole, if enhanced humans (as broadly defined as possible) are given the right to vote on an equal basis with non-enhanced humans and with other enhanced humans. While the ethical framework of responding to the appeal of the other is not a utilitarian analysis, harm to the other is of course important to consider. There is a real possibility that broad enfranchisement could, in a practical effect, lead to an objectively "bad" result of disadvantaged groups of humans, whether enhanced or non-enhanced, being further harmed - and in an extreme scenario depriving them of any right to vote at all (as happened in Canada in 1898) and to attempted genocide (as in the Holocaust). The fact that there were other considerations at play, such as the desire to appropriate land or other property, and that the grant of the franchise right was not the sole cause of the harm would not make the damage any less real. Thus, the goal of responding to the appeal of the other should mean giving such being (enhanced or nonenhanced) the opportunity to participate in the choice of whether or not they should have the right to vote and what that will mean, as well as in the very structure of government itself and what "voting" even means. Even if the intention of granting enfranchisement broadly to all types of enhanced and non-enhanced humans is good, if it would have a detrimental effect on a particular group that harm (and concern) should not be ignored. We will outline the application of a participatory engagement model to the design of voting and governance structure further below in Section 3.7. First, however, we will offer an additional example of representative voting that may be useful to include in such a process as a way to give a form of vote to those enhanced or non-enhanced humans who are not able to vote directly, and as a way to promote/amplify the voice of those who have been disenfranchised historically or who are otherwise less powerful than the dominant group (whether enhanced or non-enhanced humans).

\subsection{Representative Voting Instead of - or in Addition to-Direct Voting}

To provide the option of representative voting in a world of enhanced and nonenhanced humans, one possible way to revise the new draft of Article 21 is as follows:

60 Ref. [3]. But it is unlikely that the cause of the Nazi mistreatment of other humans was that they respected animals. Similarly, the cause of the English colonial mistreatment of the African population was not that they respected apes. There were more complex factors at play, including greed. Among other things, the Nazis wanted what they saw as the wealth of the Jews and they took it. The English wanted the wealth of Africa-and they took it. 
"The will of all beings shall be the basis of the authority of government; this will shall be expressed through universal and equal suffrage, directly and/or through representatives."

Most current governments with some form of democratic component rely on elected representatives to vote on particular laws or regulations. This is, in part, due to practical considerations. A governance concept of democracy "emerges from a particular imperative: there is paraphernalia required to make practical those decisions rendered by democracy. Accordingly, there emerges the modern distinction between governance with management, which is a tolerable version of the distinction between those with the ability to vote and those with the ability to dictate" [89]. In such models, it is important not to let ostensible considerations of efficiency obscure some elements of elitism that may be present in the representative model, ${ }^{64}$ particularly where significant wealth and privilege in a particular society is needed to even have a chance to become a viable candidate for election and then to serve in that role, with all the costs that may entail, often including maintaining two residences, one in the home state or jurisdiction and one in the capital or other location where the legislative body meets. Similarly, it is important that the elected representatives remain responsive to their constituents. "Where citizens participate in the conduct of public affairs through freely chosen representatives, it is implicit in article 25 that those representatives do in fact exercise governmental power and that they are accountable through the electoral process for their exercise of that power" [106]. For purposes of the analysis of human enhancements and voting however, we will consider a different type of representative voting-representative voting for an elected representative where the votes themselves are cast by representatives of the individual voters.

Representative voting adds an additional layer between the individual "being" for whom the vote is cast by a representative of such individual and the actual elected governmental representative. Such individual being is not actually casting a direct vote for the elected representative. Another being, or group, instead casts the vote on behalf of the individual voter. An example of one representative voting model is the Electoral College system for electing the President in the United States. A small number of electors for each state actually cast the vote for the President that will be counted, and the electors who cast such votes (who are selected by their political party) is determined based on the political party that "won" the direct votes in the state-in other words it is (generally) ${ }^{65}$ a "winner take all" system where the individual votes for President for the political party that did not receive a majority of the individual votes overall are disregarded in the final electoral vote total for the state. Although it is rare, ${ }^{66}$ this structure means the President that wins the election based on the Electoral College votes could have had the minority of the direct individual votes as a whole for the country. The system is intended to be strictly representative (by political party). Indeed, the United States Supreme Court has unanimously rejected the argument that by requiring that electors "vote" and "by ballot", the Framers of the Constitution intended that the electors' votes would reflect their own judgments versus those of their political party. ${ }^{67}$

Another option for representative voting for a particular individual being who is not able to communicate effectively could include appointing a representative who can vote on behalf of such being. In the United States, such a representative often plays a role in court proceedings involving young children, such as a custody dispute or parenting plan in the event of a divorce, or in cases involving abuse or neglect of a child. There are two different

64 John Stuart Mill offered a classic argument in favor of representative government [105].

65 Maine and Nebraska are exceptions and allocate one elector per district.

66 In the elections of 1824, 1876, 1888, 2000 and 2016 the Electoral College winners lost the popular vote. In 1824, no candidate received the majority of the electoral votes and the election was decided by the United States House of Representatives.

67 The Chiafalo v. Washington U.S. Supreme Court decision related to the so-called "faithless electors" who were fined by the State of Washington for not voting according to their party affiliation in the 2016 Election, as required by state law. The Court upheld the fine [107]. However, even the Electoral College does not attempt to represent the will of all United States residents. For example, residents of permanently inhabited United States territories such as American Samoa, Guam, the Northern Mariana Islands, Puerto Rico and the United States Virgin Islands cannot vote (either directly or indirectly) for the President and Vice President of the United States. 
models for this representative role- "guardian ad litem" and "attorney for the child", also called guardian for the child. In the "guardian ad litem" model, the guardian is appointed "ad litem", roughly meaning, appointed "for the lawsuit" or "for the action", and typically is required to represent "the best interest of the child" [108]. In such cases, considerations of the "best interest of the child," may include, for example and without limitation: "(1) The temperament and developmental needs of the child; (2) the capacity and the disposition of the parents to understand and meet the needs of the child; (3) any relevant and material information obtained from the child, including the informed preferences of the child; (4) the wishes of the child's parents as to custody; (13) the child's cultural background." 68 In the second model, the attorney for the child has a different role, as they are assigned to represent the child's wishes and advocate for their behalf. For example, in an abuse case the child may wish to stay with the abusive parent or may wish to at least have visits with such parent (including if the parent is incarcerated). The attorney for the child shares those wishes with the court and advocates for those wishes, even if the attorney personally thinks they are not in the best interests of the child. ${ }^{69}$ In an ethical model of engagement that involves attempting to respond to the appeal of the "other," the "best interests" model is less preferred than the model where a voting representative advocates for the wishes of the particular being they represent. ${ }^{70}$

For children and voting (versus lawsuits), in theory the parent or legal guardian could represent the child and cast a vote on their behalf. That is attractive for efficiency purposes but it is not clear that the parent or guardian would represent the child's wishes versus what they thought was best for the child. For example, a parent may be less concerned about climate change and voting for a candidate who is a strong environmentalist than their child (or children). ${ }^{71}$ And, moving beyond the example of children to consider the large scale needed for voting in a world of enhanced and non-enhanced human voters (and "beings" broadly defined), there may be too many beings who need representatives for each such being to have a dedicated voting representative appointed individually (at least absent future human enhancements that could make that possible). Thus, a "guardian ad litem" type of voter representative speaking for the best interests of their assigned beings when casting votes could be appointed for groups of beings. In that role, they might have a responsibility to speak only for their particular group members, roughly along the lines of the electors for a particular political party in a state, as in the United States Electoral College framework. Alternatively, a framework could be used that was

68 Connecticut General Statutes Section 46b-54(f) includes numerous factors, many of which are specific to a custody dispute or an abuse or neglect proceeding, but the general structure of the provision may be helpful to see an example framework that could be applied in voting: "[Sec. 46b-54](f). When recommending the entry of any order as provided in subsections (a) and (b) of $\S 46 \mathrm{~b}-56$, counsel or a guardian ad litem for the minor child shall consider the best interests of the child, and in doing so shall consider, but not be limited to, one or more of the following factors: (1) The temperament and developmental needs of the child; (2) the capacity and the disposition of the parents to understand and meet the needs of the child; (3) any relevant and material information obtained from the child, including the informed preferences of the child; (4) the wishes of the child's parents as to custody; ... (13) the child's cultural background; Counsel or a guardian ad litem for the minor child shall not be required to assign any weight to any of the factors considered." (emphasis added) [109]

69 Ultimately, the court determines what is in the best interests of the child, in both the guardian ad litem model and in the attorney for the child model. And, in the approach taken in the Connecticut statute, the attorney for the child should also consider the best interests of the child so the role is actually more nuanced than presented in the text above.

70 The guardian ad litem model and the advocate for the child model are still embedded in an "authorities framework" that "focuses too narrowly on state and parental control over children, reducing children's interests to those of dependency and the attainment of autonomy" [108]. "In place of this limited focus, we envision a "new law of the child" that promotes a broader range of children's present and future interests, including children's interests in parental relationships and nonparental relationships with children and other adults; exposure to new ideas; expressions of identity; personal integrity and privacy; and participation in civic life. Once articulated, these broader interests lay the foundation for a radical reconceptualization of the field of children and law. We propose a new tripartite framework of relationships, responsibilities, and rights that aims to transform how law treats children and their interactions with others" [110]. Based on the discussion in Section 3.7 below, a fresh look and potentially a new ratification of the governance framework itself would be appropriate where newly enfranchised voting beings such as children were not able to participate in the design of the original governance structure and what voting means.

71 “The UN Convention on the Rights of the Child (CRC) articulates children's rights to be heard and to participate in decisions that affect them. In spite of widespread ratification of the CRC, and the recognition of youth as a major stakeholder group with the right to participate in conversations related to climate change, children have not been adequately included in climate change decision-making at a global level, and attempts to facilitate their participation have rarely been more than tokenistic." Ref. [110] at 104-114. 
similar to the Japanese Constitutional approach in which Members of Congress are given the role of "representatives of the whole citizenry", which is understood to mean (1) "a congressman/woman is not a representative of each electoral zone, but a representative of all Japanese nationals" and (2) "he/she is not bound by voters in each electoral zone or by his/her supporters' organization." 72

Representative voting can be used to dull the impact of a particular group of humans (enhanced or non-enhanced) by giving them less of a proportional vote, and having a representative "speak" for another "being" inherently increases the risk of errors (intentional or unintentional) in even understanding what the original being wants. Thus, representative voting should be used with caution. For example, in a world of enhanced humans with extreme enhancements, such as the ability to clone/duplicate themselves at will (whether biologically, digitally or some combination thereof), representative voting might be an attractive approach proposed by other humans to avoid having such enhanced humans dominate the voting process by sheer numbers, and thereby deny effective participation to other humans. Before jumping to that "solution" to a hypothetical problem however, it would be important to consider the circumstances more carefully (and to get the views of the enhanced humans with such cloning/duplication abilities before making any ultimate decision, as will be discussed in Section 3.7 below).

It is risky to make assumptions about what an enhanced human would do or want. More importantly, it is contrary to an ethical framework of engagement that involves trying to respond to the appeal of the other. "[T]his right of the other, which should give the ultimate grounding and measure of every right, is exactly one that will always remain 'haunted' by the appeal of excessive immeasurable terms (and this always includes the danger to treat the other wrongly, especially in his otherness)." ${ }^{73}$ Can we be confident that an enhanced human who had the ability to clone/duplicate themselves at will would do so in order to impact voting in a particular election or elections? They would be faced with the consequences of having a large number of clones/duplicates. Presumably, if each clone/duplicate was a being with rights, the clones/duplicates could not just be terminated/deleted at the will of the "original". The original source of the clones/duplicates would need to coexist with the others for the remainder of its lifetime (which could be quite extended). Moreover, even if the clones/duplicates were created with the exact memories and mind of the adult original source, over time they could presumably diverge individually in their wishes and views if they had different life experiences. A single individual non-enhanced human may change their views (and their voting patterns) over time. Should we not expect that the same might be possible for clones/duplicates of an enhanced human? Alternatively, if the clones/duplicates were all under the total control of a single mind or consciousness and did not have free will, then it might be more accurate to treat the entire group as a single voting being with a single direct vote. In that case, representative voting would not be appropriate.

Although there are dangers in using representative voting as a substitute for direct voting, it can also be beneficial for the less powerful. For example, representative voting can be used as a way to amplify the voice of those beings (whether enhanced or nonenhanced) who are in a minority or who are otherwise disadvantaged in their ability to participate fully and effectively in governance due to historical factors. A combination of representative and direct voting can also be employed where each individual member of a group (such as a particular political party, religion, culture, indigenous group, or caste under current examples-and potentially unlimited future groupings in a world with extreme human enhancements) wants the group as a whole to have a voice in addition to the voice of the individual member, who may differ from the group as a whole in a particular voting situation.

72 Ref. [9] at 35 (discussing Article 43(1) of the Japanese Constitution).

73 Ref. [1] at 15. 
As a first step in considering whether representative voting is appropriate for a particular group, we must recognize and resist the temptation to declare that a group is "unable" to vote when the reality is that the group in power simply does not wish to make accommodations needed to allow such a group to vote. This has been the case for humans who were not able to physically have access to a polling location, who were not able to read or mark the ballots (or even register to vote), due to being physically different, in abilities, than those humans with political power, which could also be due to age, such as if they are very young or very old, or to a lack of formal education. In an ethical framework of engagement, it is essential to always question whether access to direct voting is being denied or limited for "practical" reasons that are only choices of convenience for the humans (enhanced or non-enhanced) in power. If that is the case, representative voting can be, at best, a provisional approach while the access issues are addressed. Representative voting in lieu of direct voting should never be assumed to be an adequate or equitable response in such a situation.

In addition, there is an inherent danger of stereotyping or assuming that a particular group will (or should) vote in a certain manner when in fact there may be many individuals or subgroups who may have very different views. This raises questions of identity and representation. ${ }^{74}$ This can be seen for example in the construction of a new constitution when India became independent from Britain. "The mechanics of representation was a serious problem facing Indian democratization, and it proved to be most challenging in the cases of Muslims and the lower castes." 75 The colonial state mediated citizenship through community affiliation and therefore "embraced a static vision of participation where the interests of individuals were established in advance." 76 This resulted in a failure "to provide for a fair and enduring solution to the problem of group diversity." It was a denial of agency, that "necessarily proceeded on the assumption that individuals within certain groups would act collectively and in specific ways." 77 India's founders therefore rejected group-based or communal representation drawn on religious lines. However, the situation was different for caste-and particularly lower caste groups. "At India's founding, the Constitution permitted reserved quotas for such groups,"78 which was not on its face consistent with the rejection of communal representation for religious groups. However, a theory that has been offered to reconcile the two approaches is to view communal representation as "suitable for societies where one was a subject rather than an agent." ${ }^{\prime 79}$ As Dr. B. R. Ambedkar, chair of the drafting committee for the new Constitution, argued, the caste system was artificially imposed to create a division of laborers into compartments. ${ }^{80}$ Thus, membership in a caste was different from a religious group in which members presumably chose to self-identify and were (at least theoretically) free to leave by their own choice when they reached an age of adulthood. Moreover, due to historical discrimination, lower-caste groups had been effectively excluded from voting. Reserved quotas were presented as a temporary option to facilitate the transition to universal and effective franchise, and communal electorates could facilitate "a new cycle of participation in which the representatives of various castes who were erstwhile isolated and therefore antisocial will be thrown into an associated life." ${ }^{\prime 1}$ In this model,

74 "As articulated in international human rights instruments, the right to effective participation can be exercised by both individuals and collectives. While collective bargaining usually increases the strength of indigenous voices in negotiations and provides for more effective participation, it is also necessary to take into account the claims of each individual belonging to an indigenous group, as dissenting views cannot always be adequately represented in collective claims." Ref. [9] at 15.

75 Ref. [111] at 111.

76 Ref. [111] at 111.

77 Ref. [111] at 138.

78 Ref. [111] at 141.

79 Ref. [111] at 142.

80 Ref. [111] at 142—citing the writings of B.R. Ambedkar to advocate for the lower caste groups, such as the Dalits.

81 Ref. [111] at 145 (quoting Ambedkar). 
a system of joint electorates combined with reserved seats might offer a path toward the extinction of caste while recognizing the current and near-term reality of the dominance of the higher castes, and allowing for individual self-determination by all through universal adult suffrage. ${ }^{82}$

Another improper path of exclusion that could occur in a scenario of representative voting is by making the ballot itself (and voter registration and information materials) only in a particular language or languages, as discussed above, or only in a certain media (such as print when the method of communication of the "other" beings were through sound, light, or gestures). Where an enhancement was so extreme that non-enhanced humans could not (yet) meaningfully communicate with the enhanced humans, representative voting might be appropriate for one - or both—groups until direct voting was possible (and even then representative voting might be appropriate as an addition to direct voting). Plants and animals provide an example of a situation where broad and effective crossspecies communication is not currently available. However, there are strong indications that animals do communicate with each other through language and in a complex social structure [112-115]. Plants may communicate also [116,117]. If that is the case, human enhancements could facilitate such cross-species communication but could also make it difficult for the enhanced human to communicate with other humans who did not have the same enhancement. This problem would be especially acute if the enhancement was not reversible. For example, it is at least theoretically possible that an enhanced human could be physically modified to be proficient in communicating with a particular type of bird or octopus (or digitally embedded in a machine learning/artificial intelligence network), but then could no longer communicate with humans who lacked similar enhancements.

Examples of representative voting that could be applied where direct voting was not possible due to basic communication challenges between enhanced humans, nonenhanced humans and other beings include, for example, the "Party for the Animals". "On 22 November 2006 the Dutch Party for the Animals was elected to the House of Representatives with 2 of the 150 seats. A worldwide first! On 5 [M]arch 2017 the Party for the Animals won 5 seats, an increase of 150 per cent. The party now has 80 elected representatives at European, national, regional and local level" [118]. As the Party explains: "The main driver of our party is to protect the interest of the weakest against the alleged right of the strongest. In all this, the animals are the most vulnerable and often come in last in a world focused on short-term interests. The mistreatment of animals and the destruction of their home take place on a larger scale than ever seen before, including factory farming, animal testing, and in nature itself. After the liberation of slaves and women, and giving rights to children, the next logical step is to take the interests of animals seriously." 83

Another example is a city in Costa Rica that gave citizenship to bees, plants and trees [121]. "Now known as "Ciudad Dulce"—Sweet City—Curridabat's urban planning has been reimagined around its non-human inhabitants. Green spaces are treated as infrastructure with accompanying ecosystem services that can be harnessed by local government and offered to residents. Geolocation mapping is used to target reforestation projects at elderly residents and children to ensure they benefit from air pollution removal and the cooling effects that the trees provide. The widespread planting of native species underscores a network of green spaces and biocorridors across the municipality, which are designed to ensure pollinators thrive." In this situation, the bees, plants and trees are not voting directly, but they are being recognized as "citizens" to whom the elected representatives must respond to "the appeal of the other", while also considering the wellbeing of human constituents as well. This is an expansion of the Japanese Constitutional model, where Members of Congress represent the whole citizenry"-meaning all Japanese

82 Ref. [111] at 146-147.

83 Ref. [118] Sue Donaldson and Will Kymlicka also offer an applied ethics political theory of relationships between animals and humans in Zoopolis: A Political Theory of Animal Rights. [119]. The pioneering work of Professor Donna J. Haraway in this area also merits deeper consideration [120]. 
nationals, not just their direct constituents or political party. ${ }^{84}$ In a world of enhanced and non-enhanced humans, such a scenario of respect and consideration for the well-being of those deemed "lesser" or "other"—or even "non-human"—is preferrable to the pet or slave options offered by Warwick as a prompt for debate. ${ }^{85}$ It is also more consistent with the extended ethical framework of engagement applied herein.

Human enhancement is here-now-and may increase in the future. When it comes to a core right to vote, and responsibility to afford others that right and consider their wishes and needs, we should question whether it is ever ethical to treat living or conscious "others" as captives, slaves or pets, and if so, under what circumstances. We should rejectas likely unethical under an extended version of the framework suggested by Loidolt-a model that in intent or effect advantages enhanced humans - even superhumans-over non-enhanced humans. Although they will not be covered in the manner they deserve at this time, potential approaches from one or more "posthumanist" perspectives also offer exciting alternatives. For example, "Posthumanism offers a generative critique of the subject/object dualism not by prioritizing one instead of the other, or assimilating one to the other, but by embracing both relationally, as intra-connected actants in an open and respondent context, which is also constantly shifting." ${ }^{\prime 86}$

For enhanced or non-enhanced humans who are not legally entitled to vote directly, or unable to vote directly using current voting methods, alternative systems of representation may be needed with the express recognition that they are inherently inadequate. In order to mitigate systematic discrimination against and/or by the enhanced humans of the future, it may be appropriate to reconsider and adjust the voting system. "Voting" in such a situation, should not be viewed just a right, but also as a responsibility toward others who may not be able to vote (or whose votes may "count" less). In a fair negotiation forum with a power imbalance (such as for a minority group), "the right to effective participation implies a duty on the part of members of the majority which is more onerous than that of minority participants." 87 The more powerful group members have a greater responsibility to make efforts to listen to, learn from and respectfully understand (with the least possible prejudice) the interests and demands of the less powerful group in order to try to achieve equality. As Loidolt has persuasively articulated, the more powerful will still likely fail to achieve true equality due to the inherent impossibility of fully understanding the appeal of the "other", but the process itself will have greater legitimacy than if the greater burden is placed on the less powerful to articulate their interests in a manner the more powerful will respect and honor.

Humans are not just the bearers of rights, but also beings that seek to adjudge and constitute "right" [1]. Such a framework suggests that less emphasis should be placed on artifacts of physical appearance, mental capacity, geographical location ${ }^{88}$, birthplace, ancestry (whether "natural" or "enhanced") and age of human bodies, or even species and organic versus inorganic or hybrid life forms. In addition, more weight should be allotted to the idea that all living beings are coexisting on a planet that has limited resources and that therefore all living beings may have responsibilities toward each other, regardless of

84 Ref. [9] at 35 .

85 For example, "one new and emerging approach is the use of legal personality to protect water systems in law through the granting of legal rights to rivers" [122]. By contrast, Professor Sandra Seubert contends that the "animal-as-citizen approach overestimates the potentials of human-animal communication and underestimates the abuse of power asymmetries. Humans can (and should) take (what they interpret as) animals' interests into account but they cannot deliberate about interest with animals on an equitable basis." Ref. [123] at 63-69.

88 Legal or practical disenfranchisement due to geographical location can occur because of lack of a permanent residence address due to poverty (such as in Japan, where homeless people are legally disenfranchised if they are not on the "resident register" [125] or due to membership in a nomadic tribe (such as for the Kuchis in Afghanistan [126]. There are also millions of "stateless" people who are not only disenfranchised but struggle in many other areas as well, including travel restrictions. "There are at least 4.2 million stateless people in the 79 countries that report them, but the U.N. agency believes that to be a severe undercount and that the problem affects many millions more" [127]. "Statelessness arises from a variety of situations, including redrawn borders, discriminatory laws that prevent women from passing on their nationality to a child, births that go unregistered, or the mass expulsion of an ethnic group" [127]. 
what they look like or how their minds work. If so, under a new Declaration of the Rights and Responsibilities of Beings, the legal (and practical) right to vote directly, or through indirect representation where such voting is not (yet) possible, could be distributed as broadly as possible, and voters would be ethically required to consider not only their own interests but also their responsibility toward other beings, particularly those who cannot vote or whose votes "count" for less.

\subsection{Participation of the "Other" in the Structure, Process and Meaning of Voting and Governance \\ "it has been said that democracy is the worst form of Government except for all those other forms that have been tried from time to time." 89}

In the context of "voting," giving a voice to the "other" in a world of enhanced and non-enhanced humans, defined as broadly as possible, including those with extreme enhancements and those with no enhancements, requires re-examining the basic framework of government with the benefit of inclusive participation. In an ethical theory of engagement, legitimization and justification is essential in a meaningful world. We must "face the appeal of the other" and determine what is "right" "from a phenomenological first-person perspective instead of the classical 'objective' third-person perspective of reciprocity." 90 If the process of constituting the world is a priori occurring in a context of legitimizing intentionality, and entire groups of enhanced and non-enhanced humans are (intentionally or unintentionally) excluded from participating in the very design of the governmental structure, then, in the ethical framework outlined by Loidolt, ${ }^{91}$ the resulting structure would not be "right" even if the end result was the same as what would be established with the benefit of their voices and judgment. Only the means can justify the ends-not vice versa. This is particularly true because, in advance, we recognize that "this right of the other, which should give the ultimate grounding and measure of every right, is exactly one that will always remain 'haunted' by the appeal of excessive immeasurable terms (and this always includes the danger to treat the other wrongly, especially in his otherness)."

"The foundation of democracy is to be seen in the human being pressing into the future and the inherent comportment towards future circumstances that are different from those of the present. In other words, it is to be found in the pre-rational, bodying along of ourselves with our distinctive way of being. Human beings have always been communal and they have always displayed a range of involvements with others of their kind. Democracy itself has its ground in one of these involvements. Probably, the involvements are those which couple the manifest tensions around decision making in emergent communities with the aspirations of individuals who seek to produce something that is beyond their own competence." ${ }^{\prime 92}$ Thus, any governmental structure and process of voting that is put in place should not only involve as many voices as possible (including both enhanced and non-enhanced humans for purposes of the present focus on human enhancements) but also must recognize it is inherently imperfect and provisional—and subject to a fresh re-examination and ratification process if it is later determined that groups were excluded from participation or new groups (or types of beings) come into existence or are recognized/discovered. There has never been an easy answer to questions about how a democratic form of government with diverse participation should be structured and operate, and it is likely to become even more difficult as we have more diverse types of

Ref. [128] at 574 .

90 Ref. [1] at 3.

91 Ref. [1] at 7.

92 Ref. [89]. The importance of participation by the less powerful is emphasized by Kawashima in the context of indigenous peoples. Drawing from the Inter-American Commission on Human Rights, Organization of American States, Proposed American Declaration on the Rights of Indigenous Peoples (1997), (OAE/Ser/L/V/11.95), she notes a key point that "indigenous peoples have a right to participate not only in the implementation and evaluation of policies, plans and programmes for national or regional development, but also in their formulation." Ref. [9] at 31. In addition, "indigenous peoples have a right to maintain and develop their own indigenous decision-making institutions and to select their representatives according to their own rules and customs." Id. 
humans, including those with extreme enhancements. Yet we must face such challenges, even knowing our response will be flawed.

Based on these considerations, our working draft Article could be modified as follows:

"The will of all beings, and responsibility toward all beings (whether voting or nonvoting), shall be the basis of the authority of government; this will, and responsibility, shall be expressed through universal and equal suffrage (directly and/or through representatives) or through such other process and method as may be developed and ratified with the universal and equitable participation of such beings."

In this theory of engagement, an inclusive process is not just for the benefit of the "other" or "lesser" participants. It is also essential for the powerful if they desire to create an ethical form of government in a diverse world, even if the new form of government is admittedly imperfect. The right to "vote" may not be sufficient, or may even be harmful, if the very structure itself is flawed. For example, the United States (and Canadian) governments were built on a foundation that intentionally benefitted wealthy white male property owners and intentionally disadvantaged indigenous peoples and white women. In part due to the challenge of "catching up" after decades of disenfranchisement, the United States federal government still hews more closely to the composition that the founders intended than the composition of the country as a whole. In 2020, of the 100 Senators, only 26 were women, three were Black, three were of Asian ethnicity (one of whom was also Black), four were Hispanic, and none were indigenous [129]. Only three Native Americans have served in the United States Senate in the history of its existence. The fact that the United States Senate official website only selected four categories to measure diversity also is an indicator of a lack of diversity. Canada also continues to try to meet the challenges of a legacy of discrimination. As Coel Kirby noted in 2018, "In the past three years the federal government has passed two-fifths of all Indigenous-related legislation since confederation. These changes implement a particular and contested constitutional vision of Canada as a single multicultural society comprised of two founding European nations and many less equal Indigenous nations." 93 In considering alternative visions, we can see "there were and are a multiplicity of ways of constituting our collective selves in common." 94

\subsubsection{The Importance of Broad Engagement and Participation for Legitimacy}

To address the challenges of a world of human enhancements in the ethical framework proposed, it is crucial to listen to alternative viewpoints. In ignoring the voices of different tribal leaders in Canada and unilaterally imposing (and then revoking) Indian enfranchisement, multiple "alternative visions of constitutional co-existence within confederation" were lost. "The Anishinaabe-dominated [c]ouncil proposed various forms of dual-nationality to reconcile membership in both their treaty-recognized nations and the Canadian state. In contrast, [another council with Haudenosaunee leadership] insisted on Haudenosaunee autonomy mediated by a special treaty relationship with the Canadian and imperial governments." ${ }^{\prime 95}$

Comparing the situation in Canada with that of India's founders, a profound difference was the leadership and participation of Dr. B. R. Ambedkar. Dr. Ambedkar was born a member of the Mahar caste, one of the lowest social groups in India-the Dalits, sometimes offensively referred to as the "untouchables". Nevertheless, he succeeded in earning his Ph.D. at Columbia University and a doctoral degree in economics from the London School of Economics. He was elected to chair the committee drafting India's constitution in $1947 .{ }^{96}$ Likely as a result of his role and advocacy for the lower castes, the Constitution as adopted

93 Ref. [8] at 4.

94 Ref. [8] at 4. Also, "[f]ocusing on and placing weight on a fair negotiation forum (and the right to effective participation which guarantees it), which requires the mutual cooperation and support of participants, could be understood as an Asian way of thinking, as opposed to a Western way of thinking, stressing unilateral assertions of an individual's right or interest." Ref. [9] at 22, footnote 7.

95 Ref. [8] at 2.

96 For additional background on Dr. Ambedkar, see [130]. 
reflected (somewhat) more of Dr. Ambedkar's views, and not those of M.K. (Mahatma) Gandhi, who was born into a more privileged caste than that of Dr. Ambedkar. ${ }^{97}$ Gandhi admired the caste system, although he thought there should be no hierarchy between castes. Dr. Ambedkar's response to Gandhi was "the outcaste is a byproduct of the caste system. There will be outcastes as long as there are castes. Nothing can emancipate the outcaste except the destruction of the caste system." 98

The challenges faced by the Ainu indigenous minority in Japan provide an additional example of what is lost (in terms of legitimacy) when the powerful disregard the appeal of the "others" who are less powerful, and what can be gained when those voices are heard and respected. One of the questions raised when the assimilationist 1899 Hokkaido Ex-Aborigines Protection Act was finally repealed in 1997, was how the Ainu should be treated, including whether they should have special representation in local and national legislative assemblies as well as a standing consultative Ainu body (which were two of the six provisions drafted by the Ainu Association of Hokkaido for inclusion in the new law). However, likely due to the increasing restriction of the participation of Ainu in the higherlevel policy making processes, ${ }^{99}$ the only provision that was ultimately incorporated related to the promotion of Ainu culture. ${ }^{100}$ One reason given for the rejection of the provision regarding representation was "the recognition of special electorates distinct from those of general citizens is very likely to violate the Constitution." ${ }^{101}$ Assuming, hypothetically, ${ }^{102}$ that the reason given was valid, then, in the participatory ethical framework being applied herein, the next question would be whether the Ainu had participated in the drafting and enactment of the Constitution that was being applied to deny them the right to special representation. If they had been able to meaningfully participate in such drafting, as was the case for the lower-caste and less powerful Dalits in the Indian Constitution where Dr. Ambedkar not only was able to participate, he was the elected chair of the drafting committee, its application to their rights and role would be legitimate. If they had not been able to participate meaningfully in the drafting of the Constitution and formulation of the framework of government, then they could reasonably demand a fresh review and ratification - with their participation — of the Constitution, which might warrant an entirely new framework or an amendment.

\subsubsection{Selected Examples of Difficult Questions That Require Broad Engagement}

In a world of enhanced and non-enhanced humans, including humans with extreme enhancements, it will be even more challenging to find an ethical approach that balances the right to vote with responsibilities toward other. Discarding any vision or alternative presented by a particular group out of hand would be itself a violation of the ethical obligation to respond to the appeal of the other. The questions raised when one becomes open to hearing the appeal of the other are typically not amenable to easy ethical solutions. Participation of diverse voices is essential for the structure enacted to be legitimate under

97 Ref. [130] at 150-151.

98 Ref. [130] at 26.

99 "It is especially regrettable that the Experts Meeting [Concerning Ainu Affairs - established in 1995 in response to the request of the first and then sole Ainu member of the Japanese Congress] did not include any Ainu members. This was pointed out by a member of the Experts Meeting, who suggested that a new Meeting be established, including Ainu persons, to contribute to the drafting process after the issuance of the report by the Experts Meeting. Nevertheless, this proposal was never realized." Ref. [9] at 38-40.

100 Ref. [9] at 32-33.

101 Ref. [9] at 34 (quoting from Section 3 in Hokkaido Utari Mondai Konwa Kai Tosin (A Report of the Round Table on a Policy for the Ainu Culture), March 1998.

102 Kawashima contends that the Japanese Constitution would, in fact, allow for special representation for the Ainu. Ref. [9] at 34-36. 
our extended ethical theory of engagement. ${ }^{103}$ As examples of the challenges involved, we will consider a few examples of the types of questions that would warrant careful review, with the benefit of broad engagement by enhanced and non-enhanced humans: (a) voting proportionality, (b) geo-political borders, and (c) temporality.

\section{Reconsidering Voting Proportionality}

How many "votes" should each being get, and should there be a difference based on country of citizenship, region or nationality-or based on whether the being is enhanced or non-enhanced (and the nature of the enhancement) or some other factors? In a direct model of "one being = one vote", an enhanced human might be able to clone themselves or, as noted above, they might distribute their consciousness in multiple human and/or siliconbased embodiments. If duplication of the identity and consciousness of an enhanced human was as simple (and unlimited) as making copies of digital works or computer programs, in theory such enhanced humans could "stack" the vote count in a manner that would not be viewed as fair to the other voters, whose votes could be rendered meaningless. A version of this problem has existed to some extent for every direct or representative democratic system of government with minorities whose votes would count "less" than the majority. It was the reason the U.S. Constitution established a hybrid approach (based on the House of Commons and House of Lords model of England) with the House of Representatives having a number of elected representatives for each state based roughly on the population of the state, and the Senate having a fixed number where each state had two Senators. But the model of rights and voting is a very particular model, and may not be the only appropriate model to consider, either historically or under our ethical framework of responding to the appeal of the other. We can also consider a model of responsibility toward others in voting, not just an individual (or communal) right to vote.

A group of humans operating as a hive mind or a single human with an extended consciousness that extended throughout a global network (both on land and in satellites) might well feel that communal voting was preferable for their well-being (and even for their very sanity), despite the fact that having one vote for each participant or "node" in the network might give them more votes. Operating by consensus might be tremendously valuable to them. This was the case in Canada during the period in the 1800s when Indians were briefly enfranchised before being disenfranchised. Certain tribal voters "were deeply split between the Conservative and Liberal parties that transformed the differences managed by chiefly consensus into factions competing in public electoral contests." ${ }^{\prime 104}$ Thus, it is important not to make assumptions about what another person or group would want or would think is best. They need to be involved in such decisions, to the extent possible.

\section{Reconsidering Political Geographical Borders as Determinants for Governance}

While laudable and a tremendous advance for the time it was written, Article 21 is likely too narrow for a world of enhanced humans under the ethical framework we are applying. For one thing, it is very likely limited to citizens through the reference to "his country" and it unduly preferences votes of "people" in that country, which means humans with extreme enhancements likely would not qualify. They might not be citizens of any country. The issue of geographic borders played a major impact in the American

103 The concept of "ancestry" itself, while frequently used as a proxy for race in discriminatory denial of enfranchisement as discussed above, may be legitimate when used by the group itself as a key cultural, social and/or religious requirement for membership in an indigenous group. See, for example, the struggle of the Hawaiian people or Kānaka Maoli to assert their sovereignty and right to self-determination, including the very right to define group membership at least in part based on ancestral terms. Ref. [131] at 2605 (the "OHA [Office of Hawaiian Affairs] constituted an attempt by the State of Hawaii to enable Kānaka Maoli self-determination. By rejecting this model, the [United States Supreme] Court in Rice demonstrated a troubling inability to understand indigenous self-governance as possible outside of federally recognized tribal governments-an oversight that continues to stifle indigenous self-governance in the U.S. territories to this day. Ultimately, as Hawaiian scholar Noelani Goodyear-Ka'ôpua writes, by invalidating Hawaiian-only voting for OHA trustees, Rice eliminated "the small measure of electoral control over resources Kānaka Maoli could collectively exercise within the settler state system.") (citations omitted). 
Revolution, as discussed above, where American Colonists felt they should be entitled to the right to vote in England as citizens. Such questions continue to be of concern.

For example, in 2018, the following question was submitted to the European Parliament, "Six EU Member States (Cyprus, Denmark, Germany, Ireland, Malta and the United Kingdom) deprive their nationals of the right to vote in national elections on account of residence abroad, on the basis of the assumption that expatriates are not affected by political decisions taken in their country of origin. These Member States also disenfranchise their nationals in European elections if they live permanently in a third country, and two of them (Ireland and the United Kingdom) even do so in respect of nationals who are resident in the EU. In some Member States (e.g., Spain and Portugal) there are insufficient or no facilities to vote from abroad, which is an obstacle to the exercise of the right to vote" [132].

Individual voting only by country or region on issues that could lead to mass extinction is problematic even in the current world because certain countries have a disproportionate impact on the global climate. In our extended ethical framework, responding to the appeal of the "other" requires consideration of the appeal of other beings regardless of where they are physically located. This is particularly evident in the case of extreme human enhancements that could allow an individual voter to "reside" in multiple countries at the same time or instantaneously change their geographic residence. We are facing catastrophic climate change impacts:

"'We're eroding the capabilities of the planet to maintain human life and life in general," said Gerardo Ceballos, an ecologist at the National Autonomous University of Mexico. The current rate of extinctions vastly exceeds those that would occur naturally. Scientists know of 543 species lost over the last 100 years, a tally that would normally take 10,000 years to accrue. 'In other words, every year over the last century we lost the same number of species typically lost in 100 years,' Dr. Ceballos said. If nothing changes, about 500 more terrestrial vertebrate species are likely to go extinct over the next two decades alone, bringing total losses equivalent to those that would have taken place naturally over 16,000 years" [133].

As it becomes clear that humans live in an increasingly interconnected and interdependent world, geographic borders could become largely irrelevant for votes that would impact global well-being (and potentially the very survival of humanity and other living beings). ${ }^{105}$ As will be discussed below, in an ethical theory of engagement, the answers to the questions of who can vote and where they can vote, even if necessarily imperfect, require the participation of and discourse among all affected humans, enhanced and non-enhanced.

As a final example of difficult/disturbing questions that require a response in an extended ethical framework of engagement, we will consider the temporality and cadence of voting.

Reconsidering Temporality/Cadence of Voting and Ratification of the Framework of Government

The temporality of voting itself should also be subject to review and consideration by enhanced and non-enhanced humans. Voting annually, or after a variable number $(n)$ years, could be ridiculous for an enhanced human who experienced time on a different scale, such as a human whose consciousness was embodied in an extended computer network. To such a human, a calendar year might be the subjective equivalent of millennia. If such humans were in the minority, the ethical theory of engagement being applied in this context would require that they have a voice in the design of the voting process itself and that other humans consider their needs and desires and not dismiss them. And if such humans became dominant in terms of wealth, numbers and political power, it would still be necessary to listen to and respect the wishes of humans without such

105 An additional concern about using geographic borders to determine voting rights is that such borders too often reflect a legacy of violent appropriation of lands and divisions in which the dispossessed lacked a meaningful voice. Ref. [134] "'They make magic lines only they can see' noted a member of the Hupacasath First Nation of British Columbia, as colonial surveyors sliced up his ancestral lands into tidy parcels, a fraction of which would become the Hupacasath's reservation." 
enhancements (whether due to poverty or self-determination that they did not wish to have such enhancements).

Looking to the future with hope that we have the opportunity to do better than the past, versus resignation that we are at or past the pinnacle of our achievements as the human race, we should periodically consider what form(s) of government are available for an inclusive and diverse population of enhanced and non-enhanced humans. We should take into account current and historical disparities and discrimination and future possibilities and what "voting" even means or should mean. Even if they were the best options available to date, which may or may not be true, existing approaches are inherently unreliable when we try to consider the diverse and potentially unlimited possibilities of a world of human enhancements - moderate to extreme-and current and future beings. The reason is that the approaches that were not designed with the input and participation of such diverse groups are fundamentally illegitimate under the extended ethical framework we are applying. They were largely designed by people of a certain wealth, gender, and religion in a particular country at a particular time. They may not represent the wide variety of perspectives that are needed in order to make self-determination meaningful in a design "from the ground up" versus "from the top down" - either currently or in the future, when there may be beings (enhanced humans or otherwise) who do not even exist today. The governed should be entitled to a voice in the design of the very system of governance, not just in its execution or in a retrofit-such as, in the United States example, by giving voting rights to male former slaves, then to women, then to indigenous peoples etc. while keeping the core (two-political party) system intact. ${ }^{106}$ They may inherit an existing system of government as a practical matter but it should not be viewed as the best option available just by virtue of its age. ${ }^{107}$ Thus, a foundational question that must be addressed in responding to the appeal of the "other" is when and how the very framework of government warrants re-examination and potentially a fresh ratification by the beings who are impacted by such framework. There is no easy answer to that question, but an answer that would be incorrect would be for the decision to be made only by one group of beings (whether enhanced humans or non-enhanced humans) without the input of the other.

The need to include a diverse group of "others" (whether enhanced or non-enhanced humans or other beings) in the design of government and what voting as a social and legal construct "means", is not a utilitarian argument or a prediction about what will result from diverse participation. The end result may not be "better" under some weighing method comparing costs and benefits. For one thing, any such weighing should be inherently suspect when the person or group doing the weighing does not represent the broader group because they tend to over-value their own interests and under-value or ignore the costs to others who are not participating in the weighing. But more fundamentally, the very premise of self-determination and enfranchisement means having the ability to make decisions that at the time or in hindsight will be seen as "bad" or "wrong." This is true at the individual level as well as at the broader citizen level.

We are responsible for the rights of others, but "at the same time we cannot point to evident legitimizing grounds-and if we do, we know that they are never enough for the ethical appeal that confronts us." 108 The "other" remains "radically impenetrable or inaccessible as other" and therefore "brings subjectivity into an anarchical and asymmetrical relation with his infinite and radical transcendence." 109 This will be true in a world of enhanced humans, as it is already true today. We deceive ourselves when we believe we

106 The two-party system in the United States has led to absurd extremes of partisan gerrymandering, such as the examples shown in Rucho v. Common Cause, in which the Supreme Court held involved "political questions" beyond the reach of the federal courts absent an equal protection (one person, one vote) violation or racial discrimination [135].

107 Dr. Ambedkar "thought of the [India] Constitution as a work in progress. Like Thomas Jefferson, he believed that unless every generation had the right to create a new constitution for itself, the earth would belong to 'the dead and not the living.'" Ref. [130] at 46 (citation omitted).

108 Ref. [1] at 18.

109 Ref. [1] at 19. 
truly understand another human being (enhanced or non-enhanced) in the way that we understand ourselves.

\section{Conclusions}

"We're out to repair the future.

We are here for the storm that's storming because what's taken matters" [136]

Loidolt concludes that "this right of the other, which should give the ultimate grounding and measure of every right, is exactly one that will always remain 'haunted' by the appeal of excessive immeasurable terms (and this always includes the danger to treat the other wrongly, especially in his otherness). However, an ethics of human rights must not be paralyzed by such a situation. It must undertake the responsibility of an urgent judgment that proves its engagement by its openness for a universality to come." ${ }^{\prime 10}$ In the context of extreme human enhancements, we will respond to the challenge of an ethics of the rights of living beings and of conscious beings-whether "still human" or "beyond human". Loidolt's "ethics of discourse" is offered as a commitment to "a critique and the ongoing process of legitimization (which would be a strategy to cope with historical and cultural relativism)" thereby opening a horizon, "where responding to the ethical appeal of the other becomes conceivable as an attitude of commitment which resists the totality of having everything at [one's] disposal."111

As the UDHR was built out of the ashes of World War II and the mass genocide whose roots could be traced to centuries of persecution (including brutal attacks on minorities and Jews who were blamed for the plague epidemic of 1348-1351 (the "Black Death"), [137] it seems appropriate to consider if we can do even better than the drafters of the UDHR as we come out of a global pandemic, mass extinctions of species and harms to humans due to climate change, and as we seek to address (and redress) the consequences of centuries of systematic legal and social discrimination, and violence, against certain people due to their skin color, gender, sexual preferences, religion, ethnicity and/or social class or caste. All of this is occurring as technology and human enhancements are advancing at a rapid rate. Just as the UDHR of 1948 was a massive step forward from the American Declaration of Independence of 1776, which enfranchised white men only and left the abomination of slavery intact, we can, and must, do better than the UDHR in years to come.

Funding: This research received no external funding.

Acknowledgments: The author greatly appreciates the guidance provided by Woodrow Barfield, a leader in the world of human enhancements-both as a technical expert and as a futurist.

Conflicts of Interest: The author declares no conflict of interest.

\section{References}

1. Loidolt, S. Notes on an Ethics of Human Rights: From the Question of Commitment to a Phenomenological Theory of Reason and Back. IWM Jr. Fellows Conf. 2005, 20, 9-24.

2. United Nations General Assembly. Universal Declaration of Human Rights; Department of State, United States of America: Minneapolis, MN, USA, 1948.

3. Taylor, S. Beasts of Burden: Animal and Disability Liberation; New Press: New York, NY, USA, 2017.

4. Brodeur, M. For composer Molly Joyce, disability is no barrier to virtuosity. Washington Post. 13 December 2020. Available online: https: / / www.washingtonpost.com/entertainment/molly-joyce-cant-use-her-left-hand-its-made-her-a-virtuosicallyunique-composer/2020/12/11/c429012a-3899-11eb-98c4-25dc9f4987e8_story.html (accessed on 9 January 2021).

5. Christopher, A.D.C. Skin Bleaching, Self-Hate, and Black Identity in Jamaica. J. Black Stud. 2003, 33, 711-718.

6. Associated Press. California sues Cisco alleging discrimination based on India's caste system. Los Angeles Times. 2 July 2020. Available online: https:/ / www.latimes.com/business/story/2020-07-02/california-sues-cisco-bias-indian-caste-system (accessed on 9 January 2021). 
7. Korff, J. Voting rights for Aboriginal people. Creative Spirits. 14 August 2020. Available online: https:/ / www.creativespirits.info/ aboriginalculture/selfdetermination/voting-rights-for-aboriginal-people (accessed on 9 January 2021).

8. Kirkby, C. Reconstituting Canada: The Enfranchisement and Disenfranchisement of 'Indians', c. 1837-1900. Univ. Tor. Law J. 2019, 69, 497-539. [CrossRef]

9. Kawashima, S. The Right to Effective Participation and the Ainu People. Int. J. Minority Group Rights 2004, 11, 21-74. [CrossRef]

10. Zhao, T.; Zhu, Y.; Tang, H.; Zie, R.; Zhu, J.; Zhang, J. Consciousness: New Concepts and Neural Networks. Front. Cell. Neurosci. 2019, 13, 302. [CrossRef] [PubMed]

11. Citizens United v. Federal Election Comm'n, 558 U.S. 310 (2010) (5-4 decision) (Supreme Court of the United States) (Opinion for the majority written by Justice Anthony M. Kennedy, joined by Chief Justice Roberts and Justices Scalia, Alito and Thomas). Available online: https:/ / supreme.justia.com/cases/federal/us/558/310/ (accessed on 9 January 2021).

12. U.S. Defense Advanced Research Projects Agency. DARPA and the Brain Initiative. Available online: https://www.darpa.mil/ program/our-research/darpa-and-the-brain-initiative (accessed on 9 January 2021).

13. Strickland, E. DARPA Wants Brain Interfaces for Able-Bodied Warfighters. In IEEE Spectrum: Technology, Engineering, and Science News; IEEE: New York, NY, USA, 10 September 2018.

14. Fontelo, P.; Hawkings, D. Ranking the Net Work of the 115th. Roll Call. 2018. Available online: https://www.rollcall.com/wealthof-congress / (accessed on 9 January 2021).

15. Cornell, S.; Leonard, G. The Partisan Republic: Democracy, Exclusion and the Fall of the Founder's Constitution, 1780s-1830s; Cambridge University Press: Cambridge, UK, 2019; p. 2.

16. Scott v. Sanford, 60 U.S. 393, 404-405 (1857) (the "Dred Scott decision") (United States Supreme Court) (Opinion for the majority written by Chief Justice Roger B. Taney) (Holding that people born as slaves did not change their status and were not entitled to freedom despite having been held as a slave in a "free" state and then in a state where slavery was illegal). Available online: https:/ / supreme.justia.com/cases/federal/us/60/393/ (accessed on 9 January 2021).

17. Haag, M. Rachel Dolezal, Who Pretended to Be Black, Is Charged with Welfare Fraud (Published 2018). The New York Times. 25 May 2018. Available online: https:/ /www.nytimes.com/2018/05/25/us/rachel-dolezal-welfare-fraud.html (accessed on 9 January 2021).

18. Cook-Martin, D.; FitzGerald, D.S. How Legacies of Racism Persist in U.S. Immigration. Sch. Strategy Netw. 2014. Available online: https:/ / scholars.org/contribution/how-legacies-racism-persist-us-immigration-policy (accessed on 9 January 2021).

19. Bridges, K. The Poverty of Privacy Rights; Stanford University Press: Stanford, CA, USA, 2017; pp. 48-49.

20. Project Citizenship Inc. v. Dep't of Homeland Security (D. Mass. Civ. 1:20-cv-11545 filed 8/17/20) (lawsuit filed in the United States Federal Court for the District of Massachusetts on 17 August 2020). Available online: https://projectcitizenship.org/wp-content/ uploads/2020/08/Project-Citizenship_Complaint_AsFiled.pdf (accessed on 9 January 2021).

21. Doherty, J. Naturalization Fee Hike Is 'A Wealth Test,' Says New Suit. Law 360. 18 August 2020. Available online: https: / / www.law360.com/articles/1302067/naturalization-fee-hike-is-a-wealth-test-says-new-suit (accessed on 9 January 2021).

22. Cahill, C.D.; Deer, S. In 1920, Native Women Sought the Vote. Here's What's Next. The New York Times. 31 July 2020. (Updated 19 August 2020). Available online: https:/ / www.nytimes.com/2020/07/31/style/19th-amendment-native-womens-suffrage. html (accessed on 9 January 2021).

23. United States Holocaust Memorial Museum. Nuremberg Race Laws. Available online: https://encyclopedia.ushmm.org/ content/en/article/nuremberg-laws (accessed on 9 January 2021).

24. Chou, V. How Science and Genetics are Reshaping the Race Debate of the 21st Century. Science in the News. 17 April 2017. Harvard University Graduate School of Arts and Sciences blog. Available online: http://sitn.hms.harvard.edu/flash/2017 / science-genetics-reshaping-race-debate-21st-century/ (accessed on 9 January 2021).

25. Bridges, K. Critical Race Theory: A Primer; Foundation Press: St. Paul, MN, USA, 2019.

26. Wines, M. Illegal Voting Gets Texas Woman 8 Years in Prison, and Certain Deportation (Published 2017). The New York Times. 10 February 2017. Available online: https:/ /www.nytimes.com/2017/02/10/us/illegal-voting-gets-texas-woman-8-years-inprison-and-certain-deportation.html (accessed on 9 January 2021).

27. Gonzalez-Barrera, A. Mexican Lawful Immigrants Among the Least Likely to Become U.S. Citizens. Pew Res. Cent. 29 June 2017. Available online: https:/ / www.pewresearch.org/hispanic/2017/06/29/mexican-lawful-immigrants-among-least-likely-tobecome-u-s-citizens / (accessed on 9 January 2021).

28. U.S. Citizenship and Immigration Service. Civics (History and Government) Questions for the Naturalization Test. (rev. January 2019). Available online: https://www.uscis.gov/sites/default/files/document/questions-and-answers/100q.pdf (accessed on 9 January 2020).

29. Onion, R. Take the Impossible "Literacy" Test Louisiana Gave Black Voters in the 1960s. Slate. 23 July 2013. Available online: https: / slate.com/human-interest/2013/06/voting-rights-and-the-supreme-court-the-impossible-literacy-test-louisianaused-to-give-black-voters.html (accessed on 9 January 2021).

30. Comstock v. Zoning Board of Appeals of Cloucester, Slip Op. 19-P-1163 at 8, fn. 11 (Opinion by Justice Milkey) (Supreme Judicial Court of Massachusetts-3 August 2020). Available online: https://www.massmunilaw.org/wp-content/uploads/2020/08/ HENRY-W.-COMSTOCK-JR.-v.-ZBA-OF-GLOUCESTER.pdf (accessed on 9 January 2021). 
31. Lorber, J. Paradoxes of Gender Redoux: Multiple Genders and the Persistence of the Binary. In Gender Reckonings: New Social Theory and Research; James, W.M., Patricia, Y.M., Michael, A.M., Raewyn, C., Eds.; New York University Press: New York, NY, USA, 2018; p. 298.

32. Jones, P. Roosters, Hawks and Dawgs: Toward an Inclusive, Embodied Eco/Feminist Psychology. Fem. Psychol. 2010, 20, 365-380. [CrossRef]

33. Singer, P. All Animals Are Equal. In Animal Rights and Human Obligations; Regan, T., Singer, P., Eds.; Prentice Hall: Englewood Cliffs, NJ, USA, 1989; pp. 148-162.

34. Jefferson, T. Declaration of Independence: A Transcription. Available online: https://www.archives.gov/founding-docs/ declaration-transcript (accessed on 9 January 2021).

35. O'Neill, K.; Herman, J. The Potential Impact of Voter Identification Laws on Transgender Voters in the 2020 General Election. UCLA School of Law Williams Inst. 2020. Available online: https:/ / escholarship.org/uc/item/1qx199j7 (accessed on 9 January 2021).

36. Hurt, E. Voter ID Laws May Disproportionately Affect Transgender Community. NPR. 29 October 2018. Available online: https: / / www.npr.org/2018/10/29/661676054/voter-id-laws-may-disproportionately-affect-transgender-community (accessed on 9 January 2021).

37. Denyer, S.; Gowen, A. There's Too Many Men: What Happens When Women Are Outnumbered on a Massive Scale. The Washington Post. 18 April 2018. Available online: https://www.washingtonpost.com/graphics/2018/world/too-many-men/ (accessed on 9 January 2021).

38. Hansen, C. 116th Congress by Party, Race, Gender, and Religion. U.S. News. 19 December 2019. Available online: https: //www.usnews.com/news/politics/slideshows/116th-congress-by-party-race-gender-and-religion (accessed on 9 January 2021).

39. Breeden, A. City of Paris Fined Nearly $\$ 110,000$ for Appointing Too Many Women. The New York Times. 22 December 2020. Available online: https://www.nytimes.com/2020/12/16/world/europe/paris-too-many-women-fine.html (accessed on 9 January 2021).

40. Erdbrink, T.; Sorensen, M.S. A Danish Children's TV Show Has This Message: Normal Bodies Look Like This. The New York Times. 7 October 2020. Available online: https:/ /www.nytimes.com/2020/09/18/world/europe/denmark-children-nudity-sexeducation.html?action=click\&algo=als_engaged_control_desk_filter\&block=editors_picks_recirc\&fellback=false\&imp_id=66 6102250\&impression_id=88bb3550-fae0-11ea-8f6c-292671e378eb\&index=0\&pgtype=Article\&region=footer\&req_id=28074295 \&surface=home-featured (accessed on 9 January 2021).

41. BBC—Science \& Nature-Human Body and Mind-Obsessions—Gallery. Available online: https://www.bbc.co.uk/science/ humanbody/mind/articles/disorders/gallery/gallery_case2.shtml (accessed on 9 January 2021).

42. Warwick, K. Superhuman Enhancements via Implants: Beyond the Human Mind. Philosophies 2020, 5, 14. [CrossRef]

43. Leckie, A. Ancillary Justice; Orbit Books Hachette Book Group: New York, NY, USA, 2013.

44. Coin, A.; Mulder, M.; Dubljević, V. Ethical Aspects of BCI Technology: What Is the State of the Art? Philosophie 2020, 5, 31. [CrossRef]

45. Asada, M. Artificial Pain May Induce Empathy, Morality, and Ethics in the Conscious Mind of Robots. Philosophies 2019, 4, 38. [CrossRef]

46. Fahn, C.W. Marketing the Prosthesis: Supercrip and Superhuman Narratives in Contemporary Cultural Representations. Philosophies 2020, 5, 11. [CrossRef]

47. Biggs, K. Augmented Reality Explorer Steve Mann Assaulted at Parisian McDonald's. TechCrunch. 16 July 2012. Available online: https: / / techcrunch.com/2012/07/16/augmented-reality-explorer-steve-mann-assaulted-at-parisian-mcdonalds / (accessed on 9 January 2021).

48. Avery, D. Killings of transgender Americans reach all-time high, rights group says. NBC News. 7 October 2020. Available online: https: / / www.nbcnews.com/feature/nbc-out/killings-transgender-americans-reach-all-time-high-rights-group-saysn1242417 (accessed on 9 January 2021).

49. Violent hate crime against disabled has risen by 41 per cent in the last year, figures suggest. Independent. 9 October 2019. Available online: https:/ / www.independent.co.uk/news/uk/home-news/disabled-hate-crime-rise-41-cent-last-year-leonard-cheshirea9148301.html (accessed on 9 January 2021).

50. Samuel, S. Humans keep directing abuse-Even racism—at robots. Vox. 2 August 2019. Available online: https:/ /www.vox.com/ future-perfect/2019/8/2/20746236/ai-robot-empathy-ethics-racism-gender-bias (accessed on 9 January 2021).

51. U.S. Department of Justice, Civil Rights Division, Disability Rights Section. ADA CHECKLIST FOR POLLING PLACES (includes checklist from 2016). Available online: https:/ / www.ada.gov / votingchecklist.htm (accessed on 9 January 2021).

52. Pendo, E. Blocked from the Ballot Box: People with Disabilities. Am. Bar Assoc. 6 June 2020. Available online: https://www. americanbar.org/groups/crsj/publications/human_rights_magazine_home/voting-in-2020/blocked-from-the-ballot-box/ (accessed on 9 January 2021).

53. Abrams, A. Absentee Ballot Applications Are Not Accessible to Voters with Disabilities in 43 States. TIME. 30 September 2020. Available online: https:/ / time.com/5894405/election-2020-absentee-ballot-applications-disability-rights / (accessed on 9 January 2021).

54. Phillip, A. A paralyzed woman flew an F-35 simulator-Using only her mind. The Washington Post. 3 March 2015. Available online: https:/ / www.washingtonpost.com/news/speaking-of-science/wp/2015/03/03/a-paralyzed-woman-flew-a-f35-fighter-jet-in-a-simulator-using-only-her-mind/ (accessed on 9 January 2021). 
55. Neuralink: Elon Musk unveils pig with chip in its brain. BBC News. 29 August 2020. Available online: https://www.bbc.com/ news/world-us-canada-53956683 (accessed on 9 January 2021).

56. Virginia, C. Innovators under 35: Visionaries. MIT Technology Review. 2020. Available online: https://www.technologyreview. com/innovator/dongjin-seo/ (accessed on 9 January 2021).

57. Dunagan, J.; Grove, J.; Halbert, D. The Neuropolitics of Brain Science and Its Implications for Human Enhancement and Intellectual Property Law. Philosophies 2020, 5, 33. [CrossRef]

58. Battaglia, F. Agency, Responsibility, Selves, and the Mechanical Mind. Philosophies. (forthcoming).

59. Lai, J.; Melmed, S.; Bond, M. Pa. Now Lets Everyone Vote by Mail. But Poor People in Philly Remain Forgotten. The Philadelphia Inquirer. 22 October 2020. Available online: https://www.inquirer.com/politics/election/a/pennsylvania-mail-ballots-election2020-poor-voters-20201022.html (accessed on 9 January 2021).

60. Norwood, C. How the pandemic has complicated voting access for millions of Native Americans. PBS News. 6 October 2020. Available online: https:// www.pbs.org/newshour/politics/how-the-pandemic-has-complicated-voting-access-for-millionsof-native-americans (accessed on 9 January 2021).

61. McCulloch, G. The Widely-Spoken Languages We Still Can't Translate Online. Wired. 28 November 2018. Available online: https: //www.wired.com/story/google-translate-wikipedia-siri-widely-spoken-languages-cant-translate/ (accessed on 9 January 2021).

62. Communication Department of the European Commission. Official Website of the European Union, Europa.com, Publications Office-Interinstitutional style guide-7.2.4. Rules governing the languages of the institutions.OP/B.3/CRI. 2019. Available online: http:/ / publications.europa.eu/code/en/en-370204.htm (accessed on 9 January 2021).

63. Federal Register, Vol 81, No. 233. Available online: https://www.justice.gov/crt/file/927231/download (accessed on 28 December 2020).

64. Ancheta, A.N. Language Accommodation and the Voting Rights Act. In Voting Rights Act Reauthorization of 2006: Perspective on Democracy, Participation, and Power; Ana, H., Ed.; Berkley Public Policy Press: Berkley, CA, USA, 2007; p. 296.

65. De Araujo, M. The Ethics of Genetic Cognitive Enhancement: Gene Editing or Embryo Selection? Philosophies 2020, 5, 20. [CrossRef]

66. Santoni de Sio, F.; Faulmuller, N.; Vincent, N. How cognitive enhancement can change our duties. Front. Syst. Neurosci. 2014, 8, 1031. [CrossRef] [PubMed]

67. Neal, J. Ranked-choice voting, explained. Harvard Law Today. 26 October 2020. Available online: https://today.law.harvard.edu/ ranked-choice-voting-explained/ (accessed on 9 January 2021).

68. Massachusetts Question 1, Nurse-Patient Assignment Limits Initiative. Ballotpedia. 2018. Available online: https://ballotpedia. org/Massachusetts_Question_1,_Nurse-Patient_Assignment_Limits_Initiative_(2018) (accessed on 9 January 2021).

69. Glausiusz, J. Were Neanderthals More Than Cousins to Homo Sapiens. Anthropology Magazine SAPIENS. 2020. Available online: https: / www.sapiens.org/biology/hominin-species-neanderthals / (accessed on 9 January 2021).

70. Hughes, J. Citizen Cyborg: Why Democratic Societies Must Respond to the Redesigned Human of the Future; Westview Press: Boulder, CO USA, 2004.

71. Korsgaard, C.M. Fellow Creatures: Kantian Ethics and Our to Animals. Tanner Lect. Hum. Values 2004, 24, 77-110. Available online: https:/ / dash.harvard.edu/handle/1/3198692 (accessed on 9 January 2021).

72. Korsgaard, C.M. Kantian Ethics, Animals, and the Law. Oxf. J. Leg. Stud. 2013, 33, 629-648. [CrossRef]

73. Maria, G. The Phenomenological Critique of Law according to Simone Goyard-Fabre. In Archive of the History of Philosophy and Social Thought; Oxford University Press: New York, NY, USA, 2016; Volume 61.

74. Gray, C.H. Cyborg Citizen: Politics in the Posthuman Age; Routledge: New York, NY, USA, 2002.

75. The trial of German major war criminals: Proceedings of the International Military Tribunal sitting at Nuremberg Germany. Available online through the Avalon Project of the Yale Law School. Available online: https://avalon.law.yale.edu/imt/12-14-45 .asp (accessed on 9 January 2021).

76. Bachrach, S.D. Introduction by Jeshajahu Weinberg, Director (1989-1995) United States Holocaust Museum. In Tell Them We Remember: The Story of the Holocaust; United States Holocaust Memorial Museum. Little, Brown: Boston, MA, USA, 1994.

77. Stone, L. Quantifying the Holocaust: Hyperintense kill rates during the Nazi genocide. Sci. Adv. 2019, 5, eaau7292. [CrossRef]

78. Mosakas, K. On the moral status of social robots: Considering the consciousness criterion. In AI E SOCIETY; Springer: Berlin/Heidelberg, Germany, 2020; Available online: https://www.researchgate.net/publication/342192401_On_the_moral_ status_of_social_robots_considering_the_consciousness_criterion (accessed on 9 January 2021).

79. Longuenesse, B. I, Me, Mine: Back to Kant and Back Again; Oxford University Press: New York, NY, USA, 2017 ; p. 163.

80. Heidegger, M. ; Capuzzi, F., Translator; Letter on “Humanism” (1949). Available online: https:/ / warwick.ac.uk/fac/arts/english/ currentstudents/undergraduate/modules/en354/syllabus/seminars/letteronhumanism1949.pdf (accessed on 9 January 2021).

81. Di Cesare, D. Heidegger and the Jews: The Black Notebooks, English edition; Polity: Cambridge, UK, 2018.

82. Tanzer, M. Heidegger on Animality and Anthropocentrism. J. Br. Soc. Phenomenol. 2016, 47, 18-32. [CrossRef]

83. Lindberg, S. Heidegger's Animal. Phänomenologische Forschungen 2004, 57-81. Available online: www.jstor.org/stable/24360638 (accessed on 9 January 2021). [CrossRef]

84. Zimmerman, M. Heidegger on Techno-Posthumanism: Revolt against Finitude, or Doing What Comes "Naturally". In Perfecting Human Futures: Transhuman Visions and Technological Imaginations; Hurlbut, J., Tirosh-Samuelson, H., Eds.; Springer VS: Hesse, Germany, 2016. [CrossRef] 
85. Johnson, A. That Was No Typo: The Median Net Worth of Black Bostonians Really Is \$8. The Boston Globe. 11 December 2020. Available online: https://www.bostonglobe.com/metro/2017/12/11/that-was-typo-the-median-net-worth-black-bostoniansreally/ze5kxC1jJelx24M3pugFFN/story.html (accessed on 9 January 2021).

86. Sorensen, M. Report Outlines 'Shocking' Wage Gap between Black Women and White Men Working in Mass. Restaurants. Boston Globe. 14 August 2020. Available online: https://www.bostonglobe.com/2020/08/14/business/report-outlines-shocking-wagegap-between-black-women-white-men-working-mass-restaurants / (accessed on 9 January 2021).

87. Onishi, N. Black Man Is Beaten on Camera, Thrusting French Police Into Spotlight. The New York Times. 4 December 2020. Available online: https:/ / www.nytimes.com/2020/12/04/world/europe/Michel-Zecler-france-police-video-beating.html (accessed on 9 January 2021).

88. Mclaughlin, R. A Meatless Dominion: Genesis 1 and the Ideal of Vegetarianism. Biblical Theol. Bull. 2017, 47, 144-154. [CrossRef]

89. Shaw, R. The Phenomenology of Democracy. Policy Futures Educ. 2009, 7, 340-348. [CrossRef]

90. Latheef, S.; Henschke, A. Can a Soldier Say No to an Enhancing Intervention? Philosophies 2020, 5, 13. [CrossRef]

91. Pugh, J.; Hannah, M. Drugs That Make You Feel Bad? Remorse-Based Mitigation and Neurointerventions. Crim. Law Philos. 2017, 11, 499-522. [CrossRef] [PubMed]

92. Allen, A. Why Do Teens Do Such Crazy Stuff? It's All in Their Brains and How They Grow. Washington Post. 1 September 2014. Available online: https:/ / www.washingtonpost.com/national/health-science/risky-behavior-by-teens-can-be-explained-inpart-by-how-their-brains-change/2014/08/29/28405df0-27d2-11e4-8593-da634b334390_story.html (accessed on 9 January 2021).

93. Lemay, K.C. Winning the Right to Vote Was the Work of Many Lifetimes. The New York Times. 13 August 2020. Available online: https:/ / www.nytimes.com/2020/08/13/us/suffrage-generations-vote.html (accessed on 9 January 2021).

94. McDaneld, J. White Suffragist Dis/Entitlement: The Revolution and the Rhetoric of Racism. Legacy 2013, 30, 243-264. [CrossRef]

95. Derrida, J. The Animal That Therefore I Am; Marie-Lous, M., David, W., Eds.; Fordham University Press: New York, NY USA, 15 April 2008.

96. Fukuyama, F. Our Posthuman Future: Consequences of the Biotechnology Revolution; Picador: New York, NY, USA, 2003.

97. Martin, P. Even with a Harvard Pedigree, Caste Follows 'like a Shadow.'. The World from PRX. 5 March 2019. Available online: https:/ / www.pri.org/stories/2019-03-05/even-harvard-pedigree-caste-follows-shadow (accessed on 9 January 2021).

98. Do Animals Have Feelings? Examining Empathy in Animals. UWA Online. 3 April 2019. (discussing research of Professor Marc Bekoff). Available online: https:/ / online.uwa.edu/news/empathy-in-animals / (accessed on 9 January 2021).

99. Hailey, B.-P. Koko, the gorilla whose sign language abilities changed our view of animal intelligence, dies at 46 . Baltimore Sun. 21 June 2018. Available online: https:/ / www.baltimoresun.com/la-sci-sn-koko-gorilla-dies-20180621-story.html (accessed on 9 January 2021).

100. Gruen, L. Entangled Empathy: An Alternative Ethic for Our Relationships with Animals; Lantern Books: New York, NY, USA, 2015.

101. Berger, M. Breaking with Some Mideast Neighbors, Iran Now Lets Mothers Give Their Citizenship to Their Children. Washington Post. 26 December 2020. Available online: https:/ / www.washingtonpost.com/world/middle_east/iran-women-refugees-rightscitizenship/2020/12/24/0b5f74b0-445d-11eb-ac2a-3ac0f2b8ceeb_story.html (accessed on 9 January 2021).

102. Crary, A. Inside Ethics: On the Demands of Moral Thought; Harvard University Press: Cambridge, MA, USA, 2016.

103. Sanford, J.B. Senator, 4th District, Letter Received by Secretary of State Frank Jordan on June 26th, 1911, for publication as part of a voters' information manual. Document is currently filed in the California State Archives under: Secretary of State Elections Papers, 1911 Special Election. Available online: https://sfpl.org/pdf/libraries/main/sfhistory/suffrageagainst.pdf (accessed on 9 January 2021).

104. Arnold, A.; Boria, S. Understanding Nazi Animal Protection and the Holocaust. Anthrozoos Multidiscip. J. Interact. People Anim. 1992, 5, 6-31. [CrossRef]

105. Mill, J.S. Considerations on Representative Government; Cambridge University Press: Cambridge, UK, 1861. [CrossRef]

106. United Nations Office of the High Commissioner for Human Rights. General Comment No. 25: The right to participate in public affairs, voting rights and the right of equal access to public service (Art. 25): 12/07/96. CCPR/C/21/Rev.1/Add.7, General Comment No. 25 regarding the United Nations International Covenant on Civil and Political Rights. Available online: https:/ / treaties.un.org/doc/publication/unts/volume\%20999/volume-999-i-14668-english.pdf (accessed on 9 January 2021).

107. Chiafalo v. Washington, No. 19-465 (U.S. Supreme Court decision) (9-0) (Justice Kagan delivered the opinion of the Court) (6 July 2020). Available online: https:/ / www.supremecourt.gov/opinions/19pdf/19-465_i425.pdf (accessed on 9 January 2021).

108. Dailey, A.C.; Rosenbury, L.A. The New Law of the Child. Yale. L. J. 2018, 127, 1448-1741.

109. State of Connecticut, Connecticut General Statutes Section 46b-54. Available online: https://www.cga.ct.gov/current/pub/ chap_815j.htm\#sec_46b-54 (accessed on 9 January 2021).

110. Vaghri, A. Climate Change, an Unwelcome Legacy: The Need to Support Children's Rights to Participate in Global Conversations. Child. Youth Environ. 2018, 28, 104-114. [CrossRef]

111. Khosla, M. Identity and Representation. In India's Founding Moment: The Constitution of a Most Surprising Democracy; Harvard University Press: Cambridge, MA, USA, 2020.

112. Meijer, E. When Animals Speak: Toward an Interspecies Democracy; Part 1 of Animals in Context; New York University Press: New York, NY, USA, 2019.

113. Meijer, E.; Watkinson, L. Animal Languages; MIT Press: Cambridge, MA, USA, 2020. 
114. McElligott, A.G.; O’Keeffe, K.H.; Green, A.C. Kangaroos Display Gazing and Gaze Alternations during an Unsolvable Problem Task. Biol. Lett. 2020, 16, 20200607. [CrossRef]

115. Godfrey-Smith, P. Other Minds: The Octopus, the Sea, and the Deep Origins of Consciousness, 1st ed.; Farrar, Straus and Giroux: New York, NY, USA, 2016.

116. Gorzelak, M.A.; Asay, A.K.; Pickles, B.J.; Simard, S.W. Inter-Plant Communication through Mycorrhizal Networks Mediates Complex Adaptive Behaviour in Plant Communities. AoB Plants 2015, 7, plv050. [CrossRef] [PubMed]

117. Ferris, J. The Social Life of Forests. New York Times. 12 December 2020. Available online: https://www.nytimes.com/interactive/ 2020/12/02/magazine/tree-communication-mycorrhiza.html (accessed on 9 January 2021).

118. Party for the Animals. Party for the Animals. Available online: https:/ / www.partyfortheanimals.com/en/who-we-are (accessed on 9 January 2021).

119. Donaldson, S.; Kymlicka, W. Zoopolis: A Political Theory of Animal Rights; Oxford University Press: Oxford, UK, 2013.

120. Haraway, D.J. "A Cyborg Manifesto" and "The Companion Species Manifesto". In Manifestly Haraway; University of Minnesota Press: Minneapolis, MN, USA, 2016.

121. Greenfield, P. Sweet City: The Costa Rica Suburb That Gave Citizenship to Bees, Plants and Trees. The Guardian. 29 April 2020. Available online: https://www.theguardian.com/environment/2020/apr/29/sweet-city-the-costa-rica-suburb-that-gavecitizenship-to-bees-plants-and-trees-aoe (accessed on 9 January 2021).

122. O'Donnell, E.L.; Talbot-Jones, J. Creating legal rights for rivers: Lessons from Australia, New Zealand and India. Ecol. Soc. 2018, 23, 1. [CrossRef]

123. Seubert, S. Politics of Inclusion: Which Conception of Citizenship for Animals? Hist. Soc. Res. 2015, 40, 154. Available online: http:/ / www.jstor.org/stable/24583241 (accessed on 9 January 2021).

124. Ferrando, F. Philosophical Posthumanism; Bloomsbury, Academic-Paperback; Bloomsbury Academic: London, UK, 2020.

125. Voting by Homeless People question on the ACE Electoral College Network online community from an ACE Project user in Japan. 13 October 2008. Responses facilitated by Stina Larserud. Available online: https://aceproject.org/electoral-advice/archive/ questions / replies/536533290 (accessed on 9 January 2021).

126. Afghan Nomads Cite Poor Representation in Elections. Gandhara RFE/RL. 11 October 2018. Available online: https:/ /gandhara. rferl.org/a/afghan-nomads-cite-poor-representation-in-elections/29538652.html (accessed on 9 January 2021).

127. Londoño, E. Stateless, She Became the Face of a Largely Invisible Plight. The New York Times. 25 December 2020. Available online: https:/ / www.nytimes.com/2020/12/25/world/americas/stateless-brazil.html (accessed on 9 January 2021).

128. Churchill, W.; Richard, M.L. Churchill by Himself: The Definitive Collection of Quotations, 1st ed; PublicAffairs: New York, NY, USA, 2008.

129. U.S. Senate. Ethnic Diversity in the Senate. (as of 2020). Available online: https://www.senate.gov/senators/EthnicDiversityintheSenate. htm (accessed on 9 January 2021).

130. Roy, A. The Doctor and the Saint: Caste, Race, and Annihilation of Caste, the Debate between b.r. Ambedkar and m.k. Gandhi; Haymarket Books: Chicago, IL, USA, 2017.

131. Pino, L.M. Colonizing History: Rice v. Cayetano and the Fight for Native Hawaiian Self-Determination. Yale L. J. 2020, 8, 2574-2605.

132. European Commission, Official Website of the European Union. European Parliament, Parliamentary Questions 21 June 2018 Question for oral answer O-000069/2018 to the Council. Available online: https://www.europarl.europa.eu/doceo/document/ O-8-2018-000069_EN.html (accessed on 9 January 2021).

133. Nuwer, R. Mass Extinctions Are Accelerating, Scientists Report. The New York Times. 1 June 2020. Available online: https: //www.nytimes.com/2020/06/01/science/mass-extinctions-are-accelerating-scientists-report.html (accessed on 9 January 2021).

134. Whyte, M. At the Addison, Contemporary Artists Push Back on Traditional Mapmaking. Boston Globe. 17 December 2020. Available online: https:/ / www.bostonglobe.com/2020/12/17/arts/marking-their-spot-contemporary-artists-push-back-traditionalmapmaking/ (accessed on 9 January 2021).

135. Rucho v. Common Cause, No. 18-422, 588 U.S.__, 139 S. Ct. 2484 (United States Supreme Court) (5-4) (2019) (Chief Justice Roberts delivered the opinion of the Court). Available online: https://supreme.justia.com/cases/federal/us/588/18-422/ (accessed on 9 January 2021).

136. Rankine, C. Weather. The New York Times. 15 June 2020. Available online: https://www.nytimes.com/2020/06/15/books/ review / claudia-rankine-weather-poem-coronavirus.html (accessed on 9 January 2021).

137. Colet, A.; Santiveri, J.X.M.; Ventura, J.R.; Saula, O.; de Galdàcano, M.E.S.; Jáuregui, C. The Black Death and Its Consequences for the Jewish Community in Tarrega: Lessons from History and Archeology; Pandemic Disease in the Medieval World: Rethinking the Black Death; The Medieval Globe Books. 1.; Arc Medieval Press: York, UK, 2014. 